\title{
Food for thought? Experimental Evidence on the Learning Impacts of a Large-Scale School Feeding Program
}

\author{
Elisabetta Aurino, Aulo Gelli, Clement Adamba, Isaac Osei-Akoto, Harold Alderman
}

\begin{abstract}
There is limited experimental evidence on the effects of large-scale, government-led interventions on human capital in resource-constrained settings. We report results from a randomized trial of the government of Ghana's school feeding. After two years, the program led to moderate average increases in math and literacy standardized scores among pupils in treatment communities, and to larger achievement gains for girls and disadvantaged children and regions. Improvements in child schooling, cognition, and nutrition constituted suggestive impact mechanisms, especially for educationally-disadvantaged groups. The program combined equitable human capital accumulation with social protection, contributing to the "learning for all" sustainable development agenda.
\end{abstract}

\begin{abstract}
Elisabetta Aurino is research fellow at the Department of Economics and Public Policy, Imperial College London (UK). Aulo Gelli is senior research fellow at the International Food Policy Research Institute (US). Clement Adamba is research fellow at the School of Education and Leadership, University of Ghana (Ghana). Isaac Osei-Akoto is senior research fellow at the Institute of Statistical, Social, and Economic Research at the University of Ghana (Ghana). Harold Alderman is senior research fellow at the International Food Policy Research Institute (US). Corresponding author: Aurino. Email: e.aurino@imperial.ac.uk
\end{abstract}

We gratefully acknowledge the enabling environment provided by the government of Ghana, particularly the Ghana School Feeding Programme (GSFP), for supporting the trial. Specific individuals include GSFP national coordinator, Hon Siedu; and Paakuna Adamu and his team, including Mrs Kuma Mintah, Mrs Anima Wilson, Mrs Susan Torson, and Mr Kwame Nuako, as well as regional and monitoring coordinators and district desk officers, who also provided significant support. The authors also thank Prof. Lesley Drake at the Partnership for Child Development (PCD), Imperial College London, for her critical role in making the trial possible; they recognize the key role played by PCD staff and associates in London and Ghana, in particular, Don Bundy, Getrude Ananse-Baiden, Daniel Mumuni, and Josephine Kiamba, Lutuf Abdul-Rahman, Rosanna Agble, Abigail Bondzie, and Fred Amese. Also, they thank Felix Asante, Kwabena M. Bosompem, Gloria Folson, Anthoni Kusi, Daniel K. Arhinful, and Irene Ayi at the University of Ghana. We also wish to thank the anonymous reviewers that have strenghtened our paper with their feedback, as well as Jere Behrman, Jacob De Hoop, Chung Truong Hoang, Pedro Rosa Dias, Jan Ross, Franco Sassi, Abhijeet Singh, and participants at seminars at 2017 IPA Conference on Education in Ghana, 2018 Italian Conference of Public Economics, 
UNICEF Innocenti Research Centre; CSAE 2019 and IZA Workshop on Gender and Family Economics 2019 for their helpful comments.

The authors have nothing to disclose. The data and do-files used in this article are available online: Aurino, Elisabetta, 2020, "Replication Data for: School feeding and child learning in Ghana.", https://doi.org/10.7910/DVN/40KVRW, Harvard Dataverse

IRB board approval was obtained by Imperial College London and the University of Ghana IRB boards.

JEL codes: I210, I24, I250, O120 


\section{Introduction}

Average learning levels for primary school pupils in low- and middle-income countries (LMICs) are dismal: for instance, only 40 percent of students in Sub-Saharan Africa (SSA) master basic literacy and numeracy at the end of primary school (World Bank 2018). Further, large disparities in achievements are present, with children from lower socioeconomic status or rural households, and, sometimes girls, lagging behind the average pupil. This "learning crisis" occurred despite unprecedented expansion in primary school access and completion: in SSA, for example, 78

percent of children at primary school age were enrolled in 2014, up from 58 percent in 1999 (World Bank 2017). Consistent with the principle of "quality education for all" underscored by the Sustainable Development Goal 4, raising average learning achievements in an equitable way is a pressing global educational objective.

Currently, there is very limited rigorous evidence focusing on the effectiveness and distributional impacts of large-scale, government-led interventions on human capital, especially in SSA (Snilstveit et al. 2015). One such intervention is school feeding, which ranks amongst the world's most common forms of social protection (Alderman, Gentilini, and Yemtsov 2018). Every day, about 368 million children receive some form of school feeding globally, for an estimated investment of $\$ 70$ billion a year (WFP 2013). In SSA, since the early 2000s, many governments have invested in school feeding as a multisectoral strategy involving education, health, and agriculture, with funding mostly stemming from Ministries of Education (Alderman and Bundy 2012; Drake et al. 2017). At an average cost of US\$54 and US\$82 per child per year in low- and middle-income countries, respectively, and often with limited poverty targeting, the share of the educational budgets devoted to school feeding is often considerable (Gelli and Daryanani 2013). 
This paper experimentally addresses whether large-scale, government-led school feeding programs can contribute to equitable learning goals in resource-constrained settings. While school feeding has a robust track record in increasing school participation (Kristjansson et al. 2015; Drake et al. 2017), experimental evidence on its effectiveness on learning is more limited and provides mixed results. Specifically, while some studies find positive effects, but often only for some specific sub-groups, others do not find any impact on test scores. Such mixed findings may be driven, on the one hand, by differences in program implementation and study designs, and, on the other, by variation in contexts. Mediating factors include the presence of educational systems that are able to support learning in face of increased school participation levels. Program outcomes may also vary according to whether the transfer is sufficient to offset opportunity costs of schooling as well as pre-existing levels of food insecurity and malnutrition (Chakraborty and Jayaraman 2019; Aurino et al. 2019). (See Appendix 1 for an overview of available experiments).

Importantly, existing experiments have all evaluated the learning effects of small-scale programs implemented as part of international food assistance, usually by the World Food Programme (WFP) or other international non-governmental organizations (NGOs), or by researchers. As an illustration, of the 17 randomized control trials (RCTs) of school feeding published since 1980 onwards that we were able to find, none was implemented by a government. Additionally, only three were implemented in more than one district (Table A.1, Appendix 1). In fact, to the best of our knowledge, the majority of evidence stemming from large-scale, government programs is based on quasi-experimental methods and set in high-income countries (Mcewan 2013; Belot and James 2011; Figlio and Winicki 2005; Anderson, Gallagher, and Ramirez Ritchie 2018), 
with the exception of a recent study on the Indian midday-meal scheme (Chakraborty and Jayaraman 2019).

Scale of implementation is a key factor to understanding effectiveness of programs that are commonly run by governments. As noted by Vivalt (2019), smaller-size programs implemented by academics and international organizations tend to report larger effect sizes than governmentled ones reaching large populations. The latter may suffer from additional challenges as compared to smaller-scale interventions, including: market equilibrium effects and spillovers (Acemoglu 2010; Filmer et al. 2018); endogenous political economy reactions (Bold et al. 2018); heterogeneity by site or in organizational effectiveness (Allcott and Mullainathan 2012; Vivalt 2015); and scale-related implementation issues, including poor monitoring, limited administrative capacity or bureaucrat incentives for the proper functioning of the program (Deaton 2010; Muralidharan and Niehaus 2017; Berry et al. 2018). Further, existing experiments were conducted during limited time periods between baseline and follow-up, and programs often employed complex or unsustainable supply chain logistics (for example, menus including perishable and/or higher-cost foods). Given these issues, the generalizability of existing evidence stemming from smaller scale, internally valid trials may fail to translate to "real-world" programs reaching millions of children daily through sizable budgetary expenditures.

Further, in the context of widespread food insecurity, school feeding programs, with their focus on children, may be more effective than alternative social protection measures targeting households, such as cash transfers or generalized food assistance, in raising learning through lowering educational costs and tackling hunger. The most vulnerable groups of learners, such as girls and children from economically disadvantaged households or areas, may benefit disproportionally more from receiving free meals than less disadvantaged pupils. This is because 
the transfer may induce steeper declines in the marginal opportunity costs of human capital investments for these groups, as compared to the average child (Akresh, Walque, and Kazianga 2013; Björkman-Nyqvist 2013). Yet, heterogeneity analysis focusing on vulnerable groups is, surprisingly, an under-investigated topic within the literature on education interventions in LMICs (Evans and Yuan 2018; Bashir et al. 2018; World Bank 2018). For school feeding, Table A.1 demonstrates that there is a lack of systematic investigation of heterogeneity across gender and socio-economic status. Finally, very few studies have assessed potential channels for impact. We tackle these questions by evaluating the average and distributional effects of the Ghana School Feeding Programme (GSFP) on child learning. The GSFP currently provides a free, hotcooked daily meal to over two million pupils in government primary schools across all districts in the country ${ }^{\mathrm{i}}$. In collaboration with the government, we conducted a RCT designed around the re-targeting and scale-up of the GSFP to the most food insecure districts in all regions of Ghana. While the overall trial was aimed at assessing program impacts on education, nutrition, and agriculture $^{\mathrm{ii}}$ (see Gelli et al., 2016), here we report on treatment effects on pre-specified educational outcomes, including child math and literacy scores, and heterogeneity in treatment effects on per-protocol population subgroups. Further, we offer some supportive evidence around possible mechanisms of program impact, including changes in schooling, cognition and nutritional status.

Ghana's learning challenges are similar to the ones currently faced by many other LMICs. First, while the government's efforts to raise schooling in the 2000s resulted in primary enrolment rates that are among the highest in SSA, average learning levels remain disappointingly low: a 2018 study highlighted that more than 80 percent and 70 percent of Grade 2 and Grade 4 students, respectively, could not read a single word or perform a two-digit subtraction (World 
Bank 2018). Second, wide inequalities in learning exist by gender, poverty, and place of residence (World Bank 2018). Further, Ghana is highly varied in terms of agroecology, ethnicity, socioeconomics, as well as political and administrative capacities. Uncovering program impacts in face of this diversity and of potential regional variation in implementation and monitoring is of interest for policy makers operating in settings characterized by high administrative and socioeconomic heterogeneity.

Following the methodology outlined in our protocol (Gelli et al. 2016), we document the following intent-to-treat (ITT) findings. After almost two academic years of implementation, exposure to school feeding led to average increases in math, literacy and a composite score of learning by about 0.15 standard deviations (s.d., hereafter). While effects sizes are comparable to estimates from a meta-analysis of smaller-scale trials of school feeding in LMICs (Snilstveit et al. 2015), we note that these moderate improvements started from a low base. Turning to impact heterogeneity, we find that the program especially benefitted educationally disadvantaged groups. Girls' math, literacy, and learning composite scores increased by more than 0.2 s.d. in school feeding communities compared to controls. Treatment effects among children living in the northern regions, the country's most disadvantaged areas, and for children from households below the poverty line at baseline ranged between 0.25 s.d. and 0.3 s.d. across all scores. These findings are likely to correspond to lower bounds of potential effects, as program take-up was imperfect and implementation challenges were present. The latter mostly related to delays in financial disbursements to the caterers that are in charge of procuring food, cooking and serving the meals. The school feeding intervention also led to increases in grade attainment for the average child, while it promoted enrolment among children from poorest households and regions. In line with the results on learning, cognitive scores of attention span and short-term 
memory also improved moderately for the average pupil, while they increased more markedly for educationally vulnerable groups. Nutritional outcomes also improved for girls and poorest children in treatment communities.

To the best of our knowledge, this is the first large-scale RCT from either a high-income or LMIC setting that investigates the effects of a nationally-mandated, government-led program on educational attainments. Thus, we contribute to the experimental literature on school meals by showing the social protection-cum-human capital accumulation of a large-scale program implemented over a relatively extended period. As discussed, the issue of scale is critical as treatment effects tend to decrease with the size of the implementing organization (Muralidharan and Niehaus 2017; Vivalt 2019). Regularity and quality in the provision of meals is key for effectiveness, as children and parents may respond to irregular or lower-quality service in multiple ways (for example, going home for lunch and not returning to school afterwards, changing school, or not attending at all). In virtue of the low-skill level of our study setting, this study adds especially to the LMICfocused literature. In particular, our paper complements the study by Chakraborty and Jayaraman (2019) by providing evidence of the learning effects of government-led school feeding in LMICs. By exploiting staggered program implementation, Chakraborty and Jayaraman's study identified moderate and positive average effects of the Indian "midday-meals" scheme on math and reading. No heterogeneity by gender or household assets was detected. Chakraborty and Jayaraman assess the program at full scale and exploit up to a five-year program exposure, which provides one of the most robust results on learning existing for LMICs. We add to this important contribution not only by employing a cleaner identification strategy, but also by providing evidence from a government program run in SSA and by analyzing potential schooling 
mechanisms. In fact, even in contexts such as Ghana where primary school enrolment is compulsory and high, and infrastructure already exists to accommodate all children, there are still concerns around potential deterioration of educational quality with negative effects on test scores due to system overload and compositional changes, especially at lower primary grades. Overcrowded classrooms and peer effects have previously confounded conclusions on the impacts of school feeding on learning in other settings where baseline enrolment was low ${ }^{\mathrm{iii}}$ (Ahmed and Arends-Kuenning 2006). However, based on our results, we deduce that the introduction of school feeding has not impaired average scores. Further, our findings suggest that in contexts characterized by wide educational inequalities such as Ghana, school feeding programs can contribute to "levelling the playing field" by raising learning outcomes especially among children at the margin (Jukes, Drake, and Bundy 2008).

More broadly, we add to the literature on social protection and human capital in LMICs. In this context, existing evidence from large-scale programs that have human capital objectives (for example, conditional cash transfers such as PROGRESA) has overwhelmingly focused on schooling rather than on learning. As summarized by Sarah Baird and coauthors, "Unlike enrolment and attendance, the effectiveness of cash transfer programmes on improving test scores is small at best" (Baird et al. 2014, p.29). We contribute to this body of work by highlighting the importance of social protection for equitable human capital outcomes. This paper is organized as follows. The next section presents the background and the study design. Then, Section III illustrates the data and identification strategy. Sections IV and V, respectively, present the ITT estimates and potential mechanisms for impact. Section VI presents some robustness checks, while Section VII concludes, including a concise discussion of costs.

\section{Background and Study Design}




\section{A. Educational Setting and the GSFP}

Despite the rapid economic growth of Ghana in the past decades, food insecurity and poverty are widespread, particularly in rural areas. During the 2000s, the country prioritized school participation through various initiatives, including the GSFP. For example, it made basic education compulsory between 5 and 15 years. These efforts resulted in a substantial expansion of basic education, with primary enrolment increasing from 61 percent in 1999 to 87 percent in 2016 (World Bank 2017). Despite these impressive achievements, an estimated 300,000 to 800,000 children are still out of primary school, mostly from households below the poverty line and from the country's northern regions (UNDP Ghana 2015). Moreover, Ghana's success in expanding schooling has not been matched by corresponding improvements in learning, which remain overwhelmingly low as compared to international standards (Ministry of Education/RTI International 2014). Wide inequalities in achievements exist by gender, poverty, and place of residence (northern viz. southern regions) (World Bank 2018).

The government of Ghana initiated the GSFP in 2005 with a 4-year program budget of over US\$200 million (GSFP 2006). Funding for the program is now integrated into the government annual budget. GSFP coordination and implementation are undertaken by a National Secretariat, with program oversight provided by the Ministry of Gender, Children and Social Protection. The program is decentralized; private caterers are awarded contracts by the GSFP to procure, prepare, and serve food to pupils in the targeted schools. Cash transfers (and, recently, electronic payments) are made from the District Assemblies to caterers based on 54 Ghana pesewas per child per day (roughly US\$0.33) every two weeks. Each caterer is responsible for procuring food from the market on a competitive basis, preparing school meals and distributing food to pupils. Supervision at the school level is undertaken by the School Implementing Committees. Delayed 
reimbursements to caterers are common, with delays as long as half a year or even a whole year (SEND-Ghana 2013). Delayed payments to caterers often result in caterers reducing the quantity or quality of food provided, or adjusting the school feeding menus, thus likely influencing program quality, and potentially, effectiveness.

\section{B. Evaluation Design}

The trial was designed around the scale-up of the GSFP based on a retargeting exercise conducted in 2012. The government's decision to retarget the GSFP followed a report that highlighted that the program overwhelmingly benefited non-poor households, with only $21 \%$ of benefits accruing to poor families (Wodon 2012). Schools and households in school catchment areas (which we call "communities" hereafter) were randomly assigned to two treatment arms: an intervention group, where the GSFP was implemented; and control, where the intervention was postponed until the study completion. The selection of study areas followed a two-step approach. First, 58 priority districts (out of the country's 170 at the time of this exercise) were identified for the scale-up of GSFP. Chosen districts had the highest shares of national poverty and food insecurity based on poverty and food insecurity rankings (see Gelli et al., [2016], for details). Second, due to the relatively small number of clusters, a restricted randomization procedure was used ${ }^{\mathrm{iv}}$. This method was employed to ensure that schools were comparable based on school- and village-level data from the Education Management Information system annual school census data from 2011-2012 (for details, see Gelli et al. [2016]). The randomisation procedure arbitrarily selected two schools in each district and randomly assigned them to the treatment and control groups. The procedure was repetead 2000 times and the research team then selected the permutation with the combination of treatment and control groups that minimized the r-squared of a regression of the selection status on school- and village-level covariates. 
Following Hayes and Moulton (2017), the variables in the restricted randomization were selected on availability and potential influence on the main study outcomes. These included school enrollment, gender ratio, classroom numbers and infrastructure conditions, accessibility, and NGO support. This step utilized a list of schools not currently covered by the program provided by the GSFP secretariat. We note that the schools were selected from separate communities, and that the distance between communities is geographically wide enough to minimise crosscommunity school enrolment, as each two villages are at least six km apart ${ }^{\mathrm{v}}$.

Using a household census at baseline, approximately 25 households with children in the 5-15 target-age group were then randomly selected for interview from each community receiving the intervention, and 20 households in the communities of the 58 control schools. For further details on the sampling procedures, see Gelli et al. (2016).

\section{Data and Sample Description}

\section{A. Timeline and Sample}

A baseline survey was undertaken in 116 communities between June and September 2013. Due to an error in the lists received by the GSFP, 25 schools in the study population, including approximately 18 percent of children in the target age group (5-15 years), had already been receiving school meals at baseline and were removed from the study population. We excluded these schools (13 controls, 12 treatment) from the follow-up. Analysis of child and household characteristics show that the excluded communities were more likely to be rural and located in the north of Ghana, and households to be slightly worse off in terms of some socio-demographic characteristics. Children from excluded communities had lower learning achievements, although all these differences were not large (Online Appendix 1). Two additional communities from the same district in Northern Ghana were excluded from the endline survey, due to logistical 
problems related to local insecurity.

Implementation in most treatment communities started in the academic year $2014 / 15$, due to bureaucratic delays (see Section III.C). The follow-up survey was conducted in February-March 2016. Given that the academic year in Ghana usually runs from August to May, the program was evaluated after roughly two academic years of implementation.

Both rounds of surveys included detailed modules on household demographics, farm and other assets, expenditures, farming and other economic activities, child anthropometry, and child selfreported $^{\text {vi }}$ education indicators for all target-age children in the household, including enrolment, attendance and grade attainment, and educational achievement tests. Of the 4,269 target-age children sampled in 2013,836 were in the last year of primary school or had already completed primary school. As such, they were not eligible to receive the intervention when implementation began and were threfore excluded from the sample. After three years, we successfully reinterviewed 92 percent of children of target-age and eligible to receive school feeding, leading to a longitudinal sample of 3,170 children. Data on schools and caterers were also collected. Data are available online (Aurino 2020).

\section{B. Balance of Baseline Covariates and Attrition at Endline}

Table 1 presents descriptive statistics of characteristics of the baseline sample by treatment arm. The average child was about 8.5 years old, with children from the school feeding arm on average a month older than control. Almost all children were enrolled in school at baseline, and a tenth of them attended private schools. The average child had completed less than two years of schooling, and about 11 percent had repeated a grade. Along with the descriptive statistics, we present balance tests to assess whether the randomization was successful in achieving balance of baseline covariates. The only difference between the two groups that was statistically significant 
at 10 percent level was age of household heads, which were about one-year-and-a-half older in the school feeding arm than in control communities. These findings, together with the relatively small size of the differences, suggests that the randomization was successful in achieving balance.

\section{[TABLE 1 ABOUT HERE]}

Table 2 presents analysis of attrition at the child level. We do not observe any inbalance in the probability of remaining in the longitudinal sample based on school feeding offer ${ }^{\text {vii }}$. Column 2 presents analysis of whether children with higher baseline test scores being more likely to be resurveyed, which did not appear to be the case. Column 3 investigates whether treatment was associated with some child characteristics in predicting likelihood of remaining in the sample. We did so by interacting treatment assignment with the background characteristics we use for heterogeneity analysis. This time, we find a joint significance of all regressors at the 5 percent level. Also, the interaction between treatment and children from poor households was moderately significant, as children from poor households in treatment areas were slightly more likely to be re-interviewed at endline (93 percent of baseline children were followed up in treatment communities, viz. 91 percent in control areas, translating in, respectively, for a total of 22 additional children lost in control areas compared to treatment). Also, boys and children from northern regions were slighlty more likely to be re-interviewed. To evaluate further the possible effects of potential attrition bias on validity of the impact estimates, the table in Online Appendix 2 presents the balance of baseline and endline characteristics across treatment groups for the full longitudinal sample, as well as for the longitudinal sample stratified by gender, household poverty and northern region. Across a wide range of baseline child and household backgrounds, there were no differences between school feeding and control arms in key characteristics at both 
baseline and endline for the longitudinal sample. The only exception is age in months for children from poor households, whereby children in school feeding areas from poor households were older at both baseline and endline than children in control areas. We address this issue by employing age-standardising test scores, as highlighted in section III.D. Thus, even if there was some concern of differential attrition by treatment in the case of children from poorest households, balance was generally maintained, particularly in light of the relatively low levels of attrition overall, which lessens concerns of a change in the sampling frame by treatment assignment due to attrition.

\section{[TABLE 2 ABOUT HERE]}

\section{Program Uptake and Implementation}

61 percent of eligible children at baseline in treatment areas reported receiving school meals in the previous week at endline, which we refer to as overall uptake rate. The uptake rate was 83 percent for those in public primary education, indicating that most children that were still in basic government education (where the program is served) did in fact receive school meals. On the other hand, fewer than two percent of children in control areas were found to have received school feeding at endline, ruling out the possibility of significant crossover, which would have hampered the experimental design. We also checked whether the introduction of the program led to children in treatment communities to switch from private to public schools to receive the program, but we did not find evidence of such instance (results available upon request). As the indicator of program uptake was self-reported by the child (or the caregiver in case of young children), we cross-checked it with mean uptake at the community level, to assess whether responses from children living in the same communities were consistent. For $80 \%$ of the communities, mean uptake was more than $70 \%$ (with half of them having an average uptake 
exceeding 90\%) (results available upon request). Only four communities, all located in the south of Ghana, had average uptake below a quarter of all eligible children, which may be a sign of poor implementation.

Eighty percent of children that reported receiving school feeding in the treatment arm at endline ate the GSFP meal at school during all days in the previous week, suggesting a fairly regular service provision. 23 percent of children in the treatment group reported they were more likely to eat less food at home on days they eat at school, indicating some substitution between meals ${ }^{\text {viii. }}$. However, only four percent reported bringing their food from the school meal to share at home. Online Appendix 3 presents correlates of child endline program uptake (independent of primary enrolment status) among children in treatment communities. Children aged 5-11 years at baseline were two times more likely to receive school feeding compared to adolescents (12-15 years at baseline), consistent with expectations of older children having progressed to secondary school or being out of school. There was no gender variation in the odds of uptake, while household poverty at baseline and northern regions were predictive of about 2 times higher chances of reporting school meals receipt. Baseline math and literacy scores were positively associated with lower odds of school feeding. This finding may be due to faster progression to secondary school for pupils that had higher achievements at baseline.

We do not have access to administrative data in program implementation, but we use data from schools and caterers to investigate variation on implementation in our sample. School data show that for some schools, the program started as originally planned in the first semester of 2013, but for the majority of schools $(n=30)$, the program started in the early months of 2014. Only one school started in February 2015. There was no indication of discontinuation of the program, however only $37 \%$ of schools reported having a copy of the district GSFP menu, potentially 
signalling varying adherence to the nutritional guidelines set by the GSFP secretariat (results available upon request). No regional differences were evident. Nearly 85 percent of caterers indicated that often payments were insufficient to cover operational costs, which led them to resort to credit to avoid changing the content and size of meals ( 83 percent), cutting on portion sizes ( 9 percent), or adopting a mix of other strategies to reduce costs (for example, reduce personnel). Further, focus groups with children, caregivers, teachers and caterers did not highlight particular irregularities in service provision, which may have been assured thanks to caterers adopting the strategies mentioned above to face the delays in disbursements (Fernandes et al. 2017).

To further understand whether the financial challenges incurred by caterers translated into poorquality meals, we analyzed data from their weekly meal logs, which provided the ingredients used for the meal served during the survey day and the following day. The most frequent meal served was a combination of a starchy food (for example, rice, yam, gari, etc.) with some type of legumes ( $46 \%$ of meals), followed by a stew or a soup combining starchy foods and animalsource proteins, mostly dry fish, chicken or meat (37\% of meals), and a starch with vegetables, mostly okra or tomato ( $9 \%$ of meals). All these meals are consistent with the GSFP menu. In one school in Brong Ahafo the caterer reported serving no meal in both days, while in only three separate instances in schools in the northern regions the caterer reported to have served only a starchy food, but only for one of the two meals surveyed. Figure 1 presents meal content between northern and southern regions, which is relevant to the heterogeneity analysis, highlighting modest variation in implementation across these areas. Although we do not have data on quantities served per child, these descriptive findings suggest that at least the implementation guidelines regarding food diversity seemed to have been followed in most cases. 
Finally, we note that the structure of the school day does not change between intervention and control schools. Without the GSFP, students should either bring food from home or buy from nearby vendors. Focus groups highlighted that without the program, however, students often go home to have lunch and may not return to school afterwards, missing out on instructional time (Fernandes et al. 2017). A similar pattern was observed in Uganda, whereby control students had much lower afternoon shift attendance than children in the school feeding arm (Alderman, Gilligan, and Lehrer 2012). Consistent with qualitative reports, analysis of time use data from our endline survey showed that pupils in intervention school spent additional time in schools as compared to control peers at endline, with larger effects for girls and children from the poorest households (30 and 50 additional minutes per day, respectively) (results available upon request).

\section{[FIGURE 1 HERE]}

\section{Measures of Child Learning}

Given the wide age range included in the target sample, learning assessments evaluated a basic set of skills in literacy and math. Each section of the test began with basic domain-specific questions that progressively increased in difficulty in order to cover different ability levels. The math assessment included questions on recognition of single or double-digit numbers, arithmetic, fractions, and basic problems (for example, how many hours in 120 minutes), while the literacy test assessed letter recognition, reading short words and sentences, and three final questions on completing a sentence with the correct item among four possible choices. The same 15-item math and literacy tests were administered in both rounds. Tests were administered at home to ensure that even children out of school were tested, enhancing internal validity. Parents or schools did not know contents of the tests, nor of their specific date and timing, hence they could not prepare children for them. Approval was obtained by parents and children at the time of test 
administration.

Test scores were standardized by child age in months for each survey round, with the control group having mean 0 and standard deviation 1 , in order to deal with the wide age groups assessed as part of the evaluation. In line with the literature (for example,, Banerjee et al. [2007]), this was achieved first by removing interviewer effects from the raw scores through a OLS regression on interviewer dummies ${ }^{\mathrm{ix}}$. The residuals from these regressions were nonparametrically estimated to obtain age-conditional means and standard deviations. We also generated a composite indicator of learning to address potential issues related to multiple testing, which should enhance statistical power to detect effects that go in the same direction (Kling, Liebman, and Katz 2006). We computed this index as an average from the normalized test scores, and then standardized again to the control group within each round ${ }^{\mathrm{x}}$. In this way, estimated ITT effects can be interpreted as the effect size relative to the control group (Banerjee et al. 2015).

Table 3 presents descriptive statistics of raw and age-standardized tests scores in the two learning domains by intervention arm for the longitudinal sample. School feeding children had larger scores in both rounds, with the difference from control being more pronounced at endline. However, none of the differences prior to the beginning of the intervention appeared to be statistically distinguishable from zero ${ }^{x i}$. The analysis of the raw scores highlights the low achievement levels in each outcome and survey round: at baseline, on average, children were not able to respond to two out of 15 questions in the math and literacy tests. This proportion increased slightly three years later, but raw endline scores were still very low, with the average pupil only being able to respond to about four out of 15 correct questions for math and literacy, which confirms Ghana's learning challenges. Consistent with these average low achievements, 
there were no ceiling effects by age at endline due to the test design: for instance, children between five and 10 years responded correctly to three questions for both math and literacy, while children aged 11-15 years were able to correctly answer to five questions on average. The analysis of age-standardized test scores at endline highlight the progress of children in the school feeding arm across all competencies.

\section{[TABLE 3 ABOUT HERE]}

Figure 2 presents the non-parametric distributions of raw (Panel A) and age-standardized (Panel B) scores in math and literacy by treatment arm at both rounds. Floor effects were present, particularly in the baseline data, highlighting the tests were challenging, particularly for the younger children. A basic reading assessment in Ghana reported similar floor effects, whereby 42 percent and 20 percent of Grade 3 and Grade 6 students, respectively, did not respond correctly to any of the test's six questions (Balwanz and Darvas 2013). Moreover, there was an improvement in mean achievement in both competences between baseline and endline, although scores were widely dispersed across the sample. This may reflect alleviation of the floor effects by the endline, but also widening of educational inequalities in the transition from primary to higher levels of education, by which the most vulnerable children tend to enter the labor market while the others progress to secondary school (De Groot et al. 2015). The figure also shows that the distribution of age-standardized achievements of the school feeding group appeared to be above the one of control at endline across the mid- to upper-end of the distribution of math and literacy.

\section{[FIGURE 2 HERE]}

Online Appendix 5 present raw scores by child gender, household poverty, and residence (south vs. north Ghana). At both rounds, there were no large and significant differences between 
girls and boys, while gaps between nonpoor and poor children were evident. The greatest disparities in baseline raw achievements, however, were based on place of residence, underscoring important geographic inequalities in educational quality between north and south Ghana. Children from the southern regions had, on average, responded to about one additional question than northern peers across both competences. This gap was substantially reduced or closed at endline. Figure 3 presents empirical distributions of age-standardized test scores by gender (Panel A), poverty (Panel B) and place of residence (Panel C). While at baseline the distribution of achievements tended to overlap between treatment and control group, highlighting balance of outcomes between treatment and control by those factors prior to the start of the program, the nonparametric distributions for the school feeding group often tended to shift toward the right at endline, particularly across the mid- to upper-ends of the distribution, indicating larger gains in learning and cognition for children receiving school feeding, as compared to those in the control group.

\section{[FIGURE 3 HERE]}

Autocorrelations of test scores between baseline and follow-up were low (math: $\rho=0.23$; literacy: $\rho=0.31$, all significant at $<0.01)^{\mathrm{xii}}$. This finding may be partially explained by some degree of measurement error, and partly by the three-year lag between the assessments. We checked whether low autocorrelation among test scores in different waves is common in longitudinal data with a different dataset (the Young Lives study from Ethiopia, India, Peru and Vietnam). Autocorrelation in vocabulary scores between 5 and 8 years in this sample was also low and roughly comparable to the one related to our literacy scores $(\rho=0.38, \mathrm{p}<0.01)$.

\section{E. Identification}


We assessed program impact through an ITT approach by comparing test scores between eligible children that were in communities randomly assigned to school feeding or the control. The ITT parameter represents the average effect of offering school feeding to children that were eligible to the program at baseline in treatment communities, regardless of whether they actually had school lunches at endline.

In the analysis plan we outlined two potential strategies to estimate the ITT parameters, depending on outcomes of interest: ANCOVA and difference-in-differences (DiD). The former improves statistical power by conditioning the endline outcome on the assignment to treatment and the baseline value of the outcome. Following McKenzie (2012) and Frison and Pocock (1992), this is our preferred estimator due to its greater efficiency (defined as retaining unbiasdness with lower variance) in estimating average treatment effects with experimental data compared to a DiD or a post-estimator approach. Gains in efficiency are more marked when outcomes have low autocorrelation, as in our case. In econometric terms, we estimate Equation 1:

$$
\text { (1) } y_{i t, j}=\alpha_{i t, j}+\beta_{1} S F_{i t, j}+\beta_{2} y_{i(t-1), j}+\theta_{r}+\varepsilon_{i t, j}
$$

where $y_{i t}, j$ and $y_{i(t-1), j}$ represent, respectively, the endline and baseline test scores (when

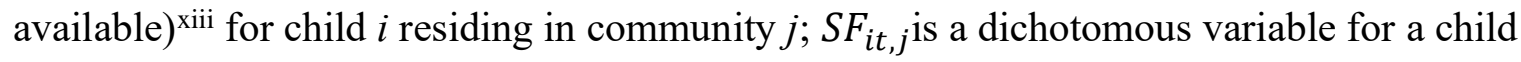
residing in a community randomly assigned to school feeding and thus uncorrelated with $y_{i(t-1), j}$; and $\theta_{r}$ is a vector of region dummies to capture region-specific unobservable characteristics or potential regional variation in quality of implementation. Standard errors were clustered at the community level, which is the unit of randomization for school feeding. $\beta_{1}$, the coefficient related to school feeding, provides the estimate of the treatment effects. Although we analyze treatment effects on pre-specified outcomes and we estimate treatment effects on a 
composite index of learning, we further address multiple hyphotesis testing by adjusting p-values through the Romano-Wolf (R-W) step-down method (Romano and Wolf 2005, 2016). These are estimated by running 2,000 iterations and clustering by community.

\section{Impact of School Feeding on Learning}

Table 4a, Panel A presents ITT estimates for the full sample employing ANCOVA. The randomized offer of school feeding led to moderately significant increases across all test scores (of about 0.15 s.d.), after adjusting for multiple hyphotesis testing. We then investigate heterogeneity in program effects. Table 4a, Panels B, C, and D, respectively, report treatment effects in models that stratify for child gender, household poverty, and geographical regions, so that we can evaluate total program effects for policy-relevant sub-populations ${ }^{\text {xiv }}$. School feeding led to sizeable and statistically significant learning gains across all competencies for girls, children from households below the poverty line, and from those living in northern Ghana. In the case of girls, math and literacy scores increased by 0.24 s.d. (R-W p $<0.01)$ and 0.2 s.d. (R-W $\mathrm{p}<0.05)$, respectively, while the composite index raised by 0.27 s.d. ( $R-W \mathrm{p}<0.01)$. By contrast, the program had a much smaller and not significant effect for boys. For children from households below the poverty line at baseline (Panel C), gains in math and in the composite scores amounted to 0.3 s.d. $(\mathrm{R}-\mathrm{W} \mathrm{p}<0.01)$, while the increases in literacy accounted to 0.23 s.d. $(\mathrm{R}-\mathrm{W} \mathrm{p}<0.05)$. Similarly, children from the northern regions had increases in math and literacy accounting to a quarter of a standard deviation each $(\mathrm{R}-\mathrm{W} \mathrm{p}<0.1)$. As for boys, gains among children from better-off households or regions were smaller and never statistically significant. For completeness, we also present DiD estimates for the main treatment effects in Table $4 \mathrm{~b}$. While the treatment effects arising from both ANCOVA and DiD are in most cases similar, as anticipated, the former estimator proved being more efficient than DiD. 


\section{[TABLES 4a and 4b ABOUT HERE]}

In addition, we investigated variation in treatment effects by age in Online Appendix 6. The latter shows that the effect of school feeding was mostly similar between children of different age groups at baseline, with the exception of math. However, in the younger cohort (children that were aged 6-11 years at baseline), effects were more precisely estimated, probably due to larger sample sizes. Also, although it was not part of the analysis plan, we assessed heterogeneity by intensity of exposure to the program based on child's age and grade at baseline. Specifically, children that were either below five years or that were enrolled in grade 5 at baseline were considered as being exposed to only one year of program, in contrast to the remaining children, which we consider as having had two years of program exposure. Across all competencies, the interaction between treatment and a dummy measuring two-year exposure was positive but never significant, perhaps due to the limited size of the one-year exposure group (Online Appendix 7). Therefore, while this is suggestive of increasing returns to program exposure, as in Chakraborty and Jayaraman (2019), our data cannot fully assess this hypothesis.

\section{Mechanisms}

While the RCT was designed to investigate educational outcomes in terms of learning, we offer a supportive exploration of possible mechanisms. Improved schooling, nutritional status, and cognitive capacities constitute potential channels through which school feeding can affect learning. First, school meals may promote enrolment, attendance and grade attainment by subsidizing educational costs through the provision of a free meal conditional on attendance. Second, by addressing hunger and micronutrient deficiencies, school feeding can positively affect children's learning via reduced morbidity-related absenteeism, better nutritional status, and increased cognitive skills in the classroom, including increased attention and memory 
(Kristjansson et al. 2015; Afridi, Barooah, and Somanathan 2019). Further, it may be plausible that teachers can be more motivated by interacting with more attentive and responsive pupils (Afridi, Barooah, and Somanathan 2013; Glewwe and Kremer 2006). The potential health impacts of school feeding may be offset by substitution between meals, or changes in the intrahousehold distribution of food, as this could be diverted away from the child receiving the free meal, though evidence of this effect is mixed (Jacoby 2002; Ahmed 2004; Chakraborty and Jayaraman 2019; Kazianga, de Walque, and Alderman 2014). Also, high heterogeneity in the health pathway may be present, with effects most likely concentrated among malnourished children (Krämer, Kumar, and Vollmer 2018; Powell et al. 1998). The remainder of this section investigates the role of these potential pathways for impact. To estimate treatment effects, we use our preferred ANCOVA estimator, which controls for the baseline values of the outcome variables (Equation 1). We note however that results are broadly unchanged when DiD is used (results available upon request). Descriptive statistics are presented in Online Appendix 8.

\section{A. Changes in Schooling}

Table 5 presents ITT estimates of school feeding on the following indicators: school enrolment in any educational level; school attendance (conditional on enrolment) as measured by the number of days the child attended school out of a five-day week; and current grade attended by the child. All of these variables were measured in the household survey with questions directed to the child or her caregiver (for young children) in both survey rounds. These outcomes are included in the study protocol as key schooling outcomes potentially affected by the intervention. Panel A reports ANCOVA estimates of school feeding for the full sample, while Panel B, C, and D report ITT effects by gender, household poverty, and geographical areas, respectively.

Increases in school enrolment emerge as an important plausible channel for impact, but only for 
children from poorest households and geographical areas. This finding is expected in contexts such as Ghana, where basic enrolment rates are already high and only the poorest children are excluded from basic education. Treatment effects for attendance and grade attainment were positive across all groups, but only significant for grade attainment of boys and non-poor children.

\section{[TABLE 5 HERE]}

\section{B. Changes in cognition}

Table 6 presents treatment effects on two indicators of child cognitive development that are listed in the protocol as potentially affected by the intervention: the standardized progressive matrices (SPM) and the digit span tests. These indicators represent two distinct cognitive dimensions: while the SPM test is an adaptation of the commonly-used Raven's progressive matrices test and measures nonverbal fluid intelligence and problem-solving ability, the digit span test assesses working memory and executive function. For each question of the SPM test, the child was given a set of images, and was asked to choose the image that would complete the picture. For the digit span test, the child was presented sequences of numbers of increasing lengths, and was asked to recall the sequences as prompted (forwards) and reversing the number order (backwards). The same 12-item tests were administered across both rounds. As for learning, we generated a composite measure of cognitive development.

School feeding had a positive effect on cognitive skills of the average child, with an increase of 0.12 s.d. in both the digit span $(\mathrm{R}-\mathrm{W} \mathrm{p}<0.1)$ and SPM $(\mathrm{R}-\mathrm{W} \mathrm{p}<0.05)$ scores, and of 0.14 s.d. in the composite score ( $\mathrm{R}-\mathrm{W} \mathrm{p}<0.05)$. Also, consistently with the results on learning, school feeding especially improved the cognitive development of disadvantaged learner groups. Specifically, the offer of school feeding led to an increase of 0.19 s.d., 0.27 s.d. and 0.25 s.d. in 
the digit span scores of treatment girls $(\mathrm{R}-\mathrm{W} \mathrm{p}<0.05)$, children from poor households $(\mathrm{R}-\mathrm{W}$ $\mathrm{p}<0.01)$ and northern Ghana $(\mathrm{R}-\mathrm{W} \mathrm{p}<0.01)$, respectively, as compared to peers in control groups. School feeding also led to increases in the SPM score of more than 0.2 s.d. among children from most disadvantaged households $(\mathrm{R}-\mathrm{W} \mathrm{p}<0.01)$ and regions $(\mathrm{R}-\mathrm{W} \mathrm{p}<0.05)$. The improvement in the composite cognitive score following the offer of school feeding accounted to 0.18 s.d. for girls ( $-\mathrm{W} p<0.05)$, and slightly less than 0.3 s.d. for children from poor households and northern Ghana $(\mathrm{R}-\mathrm{W} \mathrm{p}<0.01)$. There were also improvements in cognitive development among boys in the treatment arm: specifically, their SPM score improved by about 0.15 s.d. (R$\mathrm{W} p<0.05)$, and by 0.12 s.d. in the composite index $(\mathrm{R}-\mathrm{W} \mathrm{p}<0.1)$.

[TABLE 6 HERE]

\section{Changes in Nutritional Status}

As per our protocol, a separate paper presents impact results on nutritional status (Gelli et al. 2019). However, given the potential relevance of this channel for learning, we report core results on nutrition. The school feeding program had no effect on the height-for-age z-scores (HAZ), a marker of chronic nutritional status, and on BMI-for-age z-scores (BAZ), an indicator of concurrent nutritional status, for the whole sample. However, the program had significant effects on HAZ of girls (effect size: 0.12 s.d., $\mathrm{p}<0.05$ ) and for young children in households living below the poverty line (effect size: 0.22 s.d., $\mathrm{p}<0.05$ ). School meals also did not havean effect on the nutritional status of the aggregate school-age population in the northern regions, but the intervention increased HAZ by 0.20 s.d. in girls living in this area $(\mathrm{p}<0.01)$.

\section{Reduced Hunger in the Classroom}

We investigate whether our results might have been driven by the fact that children may perform better in learning assessments after having eaten breakfast or the school lunch (Figlio and 
Winicki 2005). Although we did not record the time in which the tests were undertaken, we check if there are differences in whether children from the treatment and control groups had breakfast before schools (which would be relevant for those children that took the test in the morning), in the total number of meals consumed by the children, and in the overall diversity of the diet (a proxy for macro- and micro-nutrient dietary quality). The latter is measured as the number of food groups consumed by the child in the previous day (Ruel 2003), so that we can also investigate issues of quality of the diet beyond frequency of meal consumption. We do not find differences in any of these indicators by arm for the full sample or for the sub-groups (Online Appendix 9). Finally, we investigated variation by treatment modality in Online Appendix 10. No substantial differences in treatment effects on educational achievements between the GSFP and HGSF were detectable, which was expected as by design child-focused outcomes were supposed to be compared only between children receiving the GSFP intervention and the control group.

\section{Discussion and conclusions}

Most countries globally invest in providing food at school as a social protection strategy to enhance children's education and health, yet experimental evidence on government programs is limited. Understanding whether large-scale, government-led school feeding is effective in raising human capital, and whether it enhances achievements for marginalized learner groups, is a critical policy question and evidence gap in order to prioritize competing intervention options available to resource-constrained governments. We report treatment effects on learning from a trial assessing a program reaching daily two million children in Ghana. After two academic years of implementation, the offer of school feeding in randomized communities led to positive 
learning gains for the average pupil. Beyond average effects, the program had larger impacts among the groups that are more vulnerable to poor learning outcomes. For girls, children from poor households, and children residing in the country's northern regions, school feeding led to dramatic improvements in learning - ranging between 0.2 s.d. to 0.3 s.d.. All estimates are likely to represent lower bounds for potential program effects due to implementation issues or partial uptake, the latter due to eligible children at baseline progressing to secondary (where the program is not served), being out of school, or being enrolled in private education. These estimates are of high policy relevance as program offering can only partially influence uptake. However, treatment-on-the-treated effects (which we did not report here) points to even larger effects.

To the best of our knowledge, this is the first study providing experimental evidence on a government's school feeding program implemented across all regions of a LMIC. These results from a SSA setting complement the large-scale evidence from India presented in Chakraborty and Jayaraman (2019): together, the two studies point to an important role of government school meals programs in raising attainments in contexts where learning outcomes are low and primary enrolment is high. In contrast to Chakraborty and Jayaraman's study, whereby large and significant learning effects for both math and reading were detected starting from the third year of program exposure, in this case program effects were already evident after two years of implementation.

A potential concern about the external validity of these results to the broader population of Ghana relates to our sampling frame. While the retargeting exercise allowed us to randomize the scale-up of the intervention, our sample draws from the country's poorest districts, which the government and donors decided to prioritize for the retargeting. Nonetheless, the high degree of 
consistence between the poverty headcount in our sample (23\%) and the 2012-13 national headcounts (24\%) (Ghana Statistical Service 2018) reassures about the comparability of our sample to nationally-representative data, which supports the view that the results have external validity. On the other hand, the fact that our sample exhibits poverty levels comparable to nationally-representative data highlights that poverty targeting of the program remains limited even after the retargeting exercise. As our findings show that the relatively poorest in our sample benefit more from the GSFP, we speculate that program impacts could increase even more if the GFSP was more strategically targeted to more disadvantaged areas or households.

We note that we cannot experimentally distinguish between the relative contribution of changes in schooling, cognition, and nutrition following the intervention. The improvements in nutrition and cognition, both inputs in the production function of human capital (Alderman et al. 1996), have likely enhanced the effects of school feeding on learning for most disadvantaged groups, which are at higher risk of malnutrition and related cognitive impairment (Powell et al., 1998). Also, school feeding had a composition effect on educational participation by attracting to school children from poorest households and regions, which are at higher risk of exclusion from basic education in Ghana. This result is consistent with other evidence from SSA, whereby reductions in education costs are effective in raising enrolment, particularly for most educationallyvulnerable groups (Aurino et al. 2018; Björkman-Nyqvist 2013; Kazianga, de Walque, and Alderman 2012). As test scores data were collected at the household-, rather than at the schoollevel, we cannot investigate further composition mechanisms related to increases in class sizes or in the proportion of less-advantaged peers starting to attend school. However, based on our results, we deduce that these potential composition effects have not impaired average test scores. In fact, our evidence highlights that for boys and non-poor children, which likely were already in 
school, school feeding favored grade attainment, and led to some moderate improvements in boys' cognition. Similarly, we cannot investigate whether complementary schooling inputs have worked jointly with school feeding to favor achievements, as, for instance, in Chakraborty and Jayaraman's study.

As mentioned, one of the main strengths of this study relates to evaluating a government program at scale. However, given the lack of administrative data on implementation, we cannot fully present direct measures of implementation variation across regions beyond the descriptive findings of Section III.C, nor can we fully explore the heterogeneity in student outcomes arising from it, which would have further spoken to the generalizability of our findings to other government-run programs. We note, however, that we control to some extent for such implementation variation in our main specification through the regional fixed effects. Another limitation relates to the fact that we cannot provide measures of treatment effects that can tie to curriculum-based or age-appropriate achievements, given the tests were designed to assess children aged 5-15 years.

The provision of a full cost-benefit/cost-effectiveness analysis of the GSFP is beyond the remit of this paper, especially given that the program is meant to affect a wide set of outcomes (education, health, social protection, agriculture), which should be assessed jointly to provide an accurate measure of cost-effectiveness (Gelli et al. 2014). Also, even if we would decide to restrict the focus on educational achievements, this exercise may be still incomplete, as the life course and intergenerational effects of gains from increased human capital (including general equilibrium effects) are not yet fully known. For instance, Bütikofer and co-authors have estimated that access to a school breakfast program run in the 1930s in Norway had positive long-term and intergenerational effects on education and earnings ${ }^{\mathrm{xv}}$ (Bütikofer, Mølland, and 
Salvanes 2018). While we leave these important issues for future research, back-of-the-envelope calculations based on the government of Ghana's transfer to caterers and an average of 200 school-days per year suggest that the program costed about US\$66 per child per year in 2015/16. While this is a very rough estimation as it does not include full implementation costs (for example, other costs at the school-level that are not included in the government budget for school feeding), this figure falls within the range of the average cost per child of school meals in LMICs reported in Gelli and Darayani (2013). Taking inflation into account, ${ }^{\text {xvi }}$ the GSFP thus compares well with other programs in LMICs in terms of costs. Also, Gelli and Darayani's estimations of program costs were based on WFP operating costs. As the WFP is the largest school feeding implementer in the world and operates through a centralized model that allows economies of scale, its cost estimates likely provide a lower bound for government programs. This is especially relevant for countries seeking food procurement within national boundaries using "home-grown" approaches, such as Ghana, in order to stimulate internal agricultural production and rural poverty reduction, at the potential cost of raising programmatic budgets through the purchase of locally-grown crops (if these are more costly).

Overall, our findings highlight the role of government-led, large-scale school feeding programs as a social protection tool with positive and equitable impacts on human capital, particularly for marginalized groups of learners. Program impacts are especially remarkable when contextualized to the normal implementation challenges related to large-scale programs run in LMICs. These challenges add to the generalizability of our findings to "real-world" interventions, which may face additional financial, implementation, and monitoring constraints than small-scale trials. Increasing average learning levels by narrowing the gaps in the distribution of achievements is critical for sustainable economic and social development. Therefore, school feeding programs 
remain important educational and social protection tools for attaining the 2030 "learning for all" agenda.

\section{References}

Acemoglu, Daron. 2010. “Theory, General Equilibrium, and Political Economy in Development Economics." Journal of Economic Perspectives 24 (3): 17-32.

https://doi.org/10.1257/jep.24.3.17.

Afridi, Farzana, Bidisha Barooah, and Rohini Somanathan. 2013. "School Meals and Classroom Effort: Evidence from India.” International Growth Center Working Paper F-35021-INC-1. London: International Growth Centre. Vol. 25. http://www.theigc.org/wpcontent/uploads/2014/09/Afridi-Et-Al-2013-Working-Paper1.pdf.

—. 2019. "Hunger and Performance in the Classroom." IZA Discussion Paper No. 12627. Bonn: IZA

Ahmed, Akhter U. 2004. "Impact of Feeding Children in School: Evidence from Bangladesh." IFPRI Working Paper 2033: 20006-1002. Washington, DC: International Food Policy Research Institute. http://www.lcgbangladesh.org/FSN/reports/IFPRI Final Report_School Feeding in Bangladesh.pdf.

Ahmed, Akhter U., and Mary Arends-Kuenning. 2006. "Do Crowded Classrooms Crowd out Learning? Evidence from the Food for Education Program in Bangladesh." World Development. https://doi.org/10.1016/j.worlddev.2005.09.011.

Akresh, Richard, D De Walque, and Harounan Kazianga. 2013. "Cash Transfers and Child Schooling: Evidence from a Randomized Evaluation of the Role of Conditionality." World Bank Policy Research Working Papers. Washington, DC: The World Bank. https://doi.org/10.1037/e547172013-001. 
Alderman, Harold, Jere R. Behrman, David R. Ross, and Richard Sabot. 1996. "The Returns to Endogenous Human Capital in Pakistan's Rural Wage Labour Market." Oxford Bulletin of Economics and Statistics 58(1):29-55. https://doi.org/10.1111/j.14680084.1996.mp58001003.x.

Alderman, Harold, and Donald Bundy. 2012. "School Feeding Programs and Development: Are We Framing the Question Correctly?" World Bank Research Observer 27 (2): 204-21. https://doi.org/10.1093/wbro/lkr005.

Alderman, Harold, Ugo Gentilini, and Ruslan Yemtsov, eds. 2018. The 1.5 Billion People Question: Food, Vouchers, or Cash Transfers? Washington, DC: The World Bank. https://openknowledge.worldbank.org/bitstream/handle/10986/27907/9781464810879.pdf. Alderman, Harold, Daniel O. Gilligan, and Kim Lehrer. 2012. "The Impact of Food for Education Programs on School Participation in Northern Uganda." Economic Development and Cultural Change 61 (1): 187-218. https://doi.org/10.1086/666949.

Allcott, Hunt, and Sendhil Mullainathan. 2012. "External Validity and Partner Selection Bias." NBER Working Paper 18373, 1-44. https://doi.org/10.1093/qje/qjv015.Advance.

Anderson, Michael L., Justin Gallagher, and Elizabeth Ramirez Ritchie. 2018. "School Meal Quality and Academic Performance.” Journal of Public Economics 168 (December): 81-93. https://doi.org/10.1016/j.jpubeco.2018.09.013.

Aurino, Elisabetta, Jean-Pierre Tranchant, Amadou Sekou Diallo, and Aulo Gelli. 2019. "School Feeding or General Food Distribution? Quasi-Experimental Evidence on the Educational Impacts of Emergency Food Assistance during Conflict in Mali." Journal of Development Studies 55(s1): 7-28.

https://www.tandfonline.com/doi/full/10.1080/00220388.2019.1687874. 
Baird, Sarah, Francisco H.G. Ferreira, Berk Özler, and Michael Woolcock. 2014. "Conditional, Unconditional and Everything in between: A Systematic Review of the Effects of Cash Transfer Programmes on Schooling Outcomes." Journal of Development Effectiveness 6 (1): 1-43. https://doi.org/10.1080/19439342.2014.890362.

Balwanz, David, and Peter Darvas. 2013. Basic Education beyond the Millennium Development Goals in Ghana: How Equity in Service Delivery Affects Educational and Learning Outcomes. Washington, DC: The World Bank. https://doi.org/10.1596/978-1-4648-0098-6. Banerjee, Abhijit, Esther Duflo, Nathanael Goldberg, Dean Karlan, Robert Osei, William Parienté, Jeremy Shapiro, Bram Thuysbaert, and Christopher Udry. 2015. “A Multifaceted Program Causes Lasting Progress for the Very Poor: Evidence from Six Countries.” Science 348 (6236). https://doi.org/10.1126/science.1260799.

Banerjee, Abhijit V., Shawn Cole, Esther; Duflo, and Leigh Linden. 2007. "Remedying Education: Evidence from Two Randomized Experiments in India.” The Quarterly Journal of Economics 122 (3): 1235-64. https://doi.org/10.1162/qjec.122.3.1235.

Bashir, Sajitha, Marlaine Lockheed, Elizabeth Ninan, and Jee-Peng Tan. 2018. Facing Forward: Schooling for Learning in Africa. Washington, DC: World Bank. https://doi.org/10.1596/978-1-4648-1260-6.

Belot, Michèle, and Jonathan James. 2011. "Healthy School Meals and Educational Outcomes." Journal of Health Economics 30 (3): 489-504. https://doi.org/10.1016/J.JHEALECO.2011.02.003.

Berry, James, S. Metha, P. Mukherjee, H. Ruebeck, and G. Kartini Shastry. 2018. "Inputs, Monitoring and Crowd-Out in India School-Based Health Interventions.” S-89206-INC-2. London: International Growth Center 
Björkman-Nyqvist, Martina. 2013. "Income Shocks and Gender Gaps in Education: Evidence from Uganda." Journal of Development Economics 105 (November): 237-53. https://doi.org/10.1016/j.jdeveco.2013.07.013.

Bold, Tessa, Mwangi Kimenyi, Germano Mwabu, Alice Ng'ang'a, and Justin Sandefur. 2018. "Experimental Evidence on Scaling up Education Reforms in Kenya." Journal of Public Economics 168 (December): 1-20. https://doi.org/10.1016/J.JPUBECO.2018.08.007.

Bruhn, Miriam, and David McKenzie. 2009. "In Pursuit of Balance: Randomization in Practice in Development Field Experiments." American Economic Journal: Applied Economics 1(4): 200-232. https://doi.org/10.1257/app.1.4.200.

Bütikofer, Aline, Eirin Mølland, and Kjell G. Salvanes. 2018. "Childhood Nutrition and Labor Market Outcomes: Evidence from a School Breakfast Program." Journal of Public Economics 168 (December): 62-80. https://doi.org/10.1016/j.jpubeco.2018.08.008.

Chakraborty, Tanika, and Rajshri Jayaraman. 2019. "School Feeding and Learning Achievement: Evidence from India's Midday Meal Program.” Journal of Development Economics, 139(C): 249-265. https://doi.org/10.1016/J.JDEVECO.2018.10.011.

De Groot, Richard, Sudhanshu Handa, Michael Park, Robert Osei Darko, Isaac Osei-Akoto, Garima Bhalla, and Luigi Peter Ragno. 2015. "Heterogeneous Impacts of an Unconditional CashTransfer Programme on Schooling: Evidence from the Ghana LEAP Programme.” Innocenti Working Paper No. 2015-10. Florence: UNICEF Office of Research - Innocenti.

Deaton, Angus. 2010. “Instruments, Randomization, and Learning about Development." Journal of Economic Literature 48 (2): 424-55. https://doi.org/10.1257/jel.48.2.424.

Drake, Lesley, Meena Fernandes, Elisabetta Aurino, Josephine Kiamba, Boitshepo Giyose, Carmen Burbano, Harold Alderman, Lu Mai, Arlene Mitchell, and Aulo Gelli. 2017. 
"School Feeding Programs in Middle Childhood and Adolescence." In Disease Control Priorities 3, edited by D. Bundy, N. De Silva, S. Horton, D. Jamison, and G.C. Patton. Washington, DC: The World Bank. http://dcp-3.org/sites/default/files/chapters/DCP3 CAHD_Ch 12.pdf.

Duflo, Esther;, Pascaline Dupas, and Michael Kremer. 2017. “The Impact of Free Secondary Education: Experimental Evidence from Ghana." https://www.povertyaction.org/sites/default/files/publications/DDK_GhanaScholarships.pdf.

Evans, D. K., and F. Yuan. 2018. "Commentary.” In Learning at the Bottom of the Pyramid., edited by Daniel A. Wagner, Sharon Wolf, and Robert F. Boruch, 232-34. Paris: UNESCO.

Fernandes, Meenakshi, Gloria Folson, Elisabetta Aurino, and Aulo Gelli. 2017. "A Free Lunch or a Walk Back Home? The School Food Environment and Dietary Behaviours among Children and Adolescents in Ghana." Food Security 9 (5): 1-18. https://doi.org/10.1007/s12571-017-0712-0.

Figlio, David N., and Joshua Winicki. 2005. "Food for Thought: The Effects of School Accountability Plans on School Nutrition.” Journal of Public Economics 89 (2-3): 381-94. https://doi.org/10.1016/J.JPUBECO.2003.10.007.

Filmer, Deon P., Jed Friedman, Eeshani Kandpal, and Junko Onishi. 2018. “General Equilibrium Effects of Targeted Cash Transfers: Nutrition Impacts on Non-Beneficiary Children.” 8377. Policy Research Working Paper. Vol. 8377. Washington, D.C: World Bank. http://documents.worldbank.org/curated/en/989031522077749796/General-equilibriumeffects-of-targeted-cash-transfers-nutrition-impacts-on-non-beneficiary-children.

Frison, Lars, and Stuart J Pocock. 1992. "Repeated Measures in Clinical Trials: Analysis Using Mean Summary Statistics and Its Implications for Design.” Statistics in Medicine 11 (13): 
1685-1704. https://doi.org/10.1002/sim.4780111304.

Gelli, A., E. Masset, G. Folson, A. Kusi, D.K. Arhinful, F. Asante, I. Ayi, et al. 2016.

"Evaluation of Alternative School Feeding Models on Nutrition, Education, Agriculture and Other Social Outcomes in Ghana: Rationale, Randomised Design and Baseline Data.” Trials 17 (1). https://doi.org/10.1186/s13063-015-1116-0.

Gelli, Aulo, Elisabetta Aurino, Gloria Folson, Daniel Arhinful, Clement Adamba, Isaac OseiAkoto, Edoardo Masset, et al. 2019. “A School Meals Program Implemented at Scale in Ghana Increases Height-for-Age during Midchildhood in Girls and in Children from Poor Households: A Cluster Randomized Trial.” The Journal of Nutrition 149(8): 1434-1442. https://doi.org/10.1093/jn/nxz079.

Gelli, Aulo, and Roshan Daryanani. 2013. "Are School Feeding Programs in Low-Income Settings Sustainable? Insights on the Costs of School Feeding Compared with Investments in Primary Education." Food and Nutrition Bulletin 34 (3): 310-17.

Gelli, Aulo, Francisco Espejo, Jing Shen, and Elizabeth Kristjansson. 2014. "Putting It All Together: Aggregating Impacts of School-Feeding Programmes on Education, Health and Nutrition: Two Proposed Methodologies." WIDER Working Paper Series. Helsinki: WIDER. https://ideas.repec.org/p/unu/wpaper/wp2014-036.html.

Ghana Statistical Service. 2018. "Ghana Living Standards Survey (GLSS7): Poverty Trends in Ghana; 2005-2017.” Accra: Ghana Statistical Service.

Glewwe, Paul, and Michael Kremer. 2006. "Chapter 16 Schools, Teachers, and Education Outcomes in Developing Countries." Handbook of the Economics of Education 2: 9451017. https://doi.org/10.1016/S1574-0692(06)02016-2.

Graff Zivin, Joshua, Solomon M. Hsiang, and Matthew Neidell. 2018. "Temperature and Human 
Capital in the Short and Long Run." Journal of the Association of Environmental and Resource Economists 5 (1): 77-105. https://doi.org/10.1086/694177.

GSFP. 2006. “Ghana School Feeding Programme. Programme Document 2007-2010.” Accra: Ghana School Feeding Programme.

Hayes, Richard J., and Lawrence H. Moulton. 2017. Cluster Randomised Trials. 2nd ed. Boca Raton: Chapman and Hall/CRC.

Jacoby, Hanan G. 2002. "Is There an Intrahousehold ' Flypaper Effect '? Evidence from a School Feeding Programme.” Economic Journal 112 (476): 196-221.

Jukes, Matthew, Lesley Drake, and Donal Bundy, eds. 2008. School Health, Nutrition and Education for All: Levelling the Playing Field. Wallingford: CABI Publishing. https://doi.org/http://dx.doi.org/10.1079/9781845933111.0011.

Kazianga, H., D. de Walque, and H. Alderman. 2012. "Educational and Child Labour Impacts of Two Food-for-Education Schemes: Evidence from a Randomised Trial in Rural Burkina Faso." Journal of African Economies 21 (5): 723-60. https://doi.org/10.1093/jae/ejs010. Kazianga, Harounan, Damien de Walque, and Harold Alderman. 2014. "School Feeding Programs, Intrahousehold Allocation and the Nutrition of Siblings: Evidence from a Randomized Trial in Rural Burkina Faso.” Journal of Development Economics 106 (January): 15-34. https://doi.org/10.1016/j.jdeveco.2013.08.007.

Kling, Jeffrey R, Jeffrey B Liebman, and Lawrence F Katz. 2006. "Experimental Analysis of Neighborhood Effects." Econometrica, no. June: 1-34. https://doi.org/10.1111/j.14680262.2007.00733.x.

Krämer, Marion; Kumar, Santosh; Vollmer, Sebastian. 2018. "Improving Children Health and Cognition: Evidence from School-Based Nutrition Intervention in India.” 203. GLO 
Discussion Paper No. 203. Maastricht: Global Labor Organization.

Kristjansson, Elizabeth, Damian K Francis, Selma Liberato, Maria Benkhalti Jandu, Vivian Welch, Malek Batal, Trish Greenhalgh, et al. 2015. "Food Supplementation for Improving the Physical and Psychosocial Health of Socio-Economically Disadvantaged Children Aged Three Months to Five Years (Review)." Cochrane Database of Systematic Reviews, no. 3: CD009924. https://doi.org/10.1002/14651858.CD009924.pub2.

Mcewan, Patrick. 2013. "The Impact of Chile's School Feeding Program on Education Outcomes." Economics of Education Review 32: 122-39. https://doi.org/10.1016/j.econedurev.2012.08.006.

McKenzie, David. 2012. "Beyond Baseline and Follow-up: The Case for More $\mathrm{T}$ in Experiments." Journal of Development Economics 99 (2): 210-21. https://doi.org/10.1016/j.jdeveco.2012.01.002.

Ministry of Education \& RTI International. 2014. "Ghana 2013 National Education Assessment Technical Report | Global Reading Network.” https://globalreadingnetwork.net/eddata/ghana-2013-national-education-assessmenttechnical-report.

Muralidharan, Karthik, and Paul Niehaus. 2017. "Experimentation at Scale.” Journal of Economic Perspectives 31 (4): 103-24. https://doi.org/10.1257/jep.31.4.103.

Powell, C A, S P Walker, S M Chang, and S M Grantham-McGregor. 1998. "Nutrition and Education: A Randomized Trial of the Effects of Breakfast in Rural Primary School Children." The American Journal of Clinical Nutrition 68 (4): 873-79.

Romano, Joseph P., and Michael Wolf. 2005. "Stepwise Multiple Testing as Formalized Data Snooping." Econometrica 73(4): 1237-1282. https://doi.org/10.1111/j.1468- 
0262.2005.00615.x

. 2016. "Efficient Computation of Adjusted P-Values for Resampling-Based Stepdown Multiple Testing." Statistics and Probability Letters 113: 38-40.

https://doi.org/10.1016/j.spl.2016.02.012.

Ruel, M.T. 2003. “Operationalizing Dietary Diversity: A Review of Measurement Issues and Research Priorities.” Journal of Nutrition 133: 3911S-3926S.

SEND-Ghana. 2013. "Ghana School Feeding Programme: Way Forward.”Accra: Send.

Snilstveit, Birte, Jennifer Stevenson, Daniel Phillips, Martina Vojtkova, Emma Gallagher, Tanja Schmidt, Hannah Jobse, Maisie Geelen, Maria Grazia Pastorello, and John Eyers. 2015. "Interventions for Improving Learning Outcomes and Access to Education in Low- and Middle-Income Countries: A Systematic Review.” London: 3ie.

UNDP Ghana. 2015. “2015 Ghana Millennium Development Goals Report.” Accra. http://www.gh.undp.org/content/ghana/en/home/library/poverty/2015-ghana-millenniumdevelopment-goals-report.html.

Vivalt, Eva. 2015. "Heterogeneous Treatment Effects in Impact Evaluation.” American Economic Review 105 (5): 467-70. https://doi.org/10.1257/aer.p20151015.

—. 2019. "How Much Can We Generalize from Impact Evaluations ?" Journal European Economic Association. Forthcoming

WFP. 2013. State of School Feeding Worldwide 2013. Rome: World Food Programme.

Wodon, Quentin, ed. 2012. Improving the Targeting of Social Programs in Ghana. Washington, DC: The World Bank. https://doi.org/10.1596/978-0-8213-9593-6.

World Bank. 2017. "World DataBank: Education Statistics - All Indicators." 2017. http://databank.worldbank.org/data/reports.aspx?source=education-statistics- -all- 
indicators\#.

. 2018. "World Development Report 2018: Learning to Realize Education's Promise." Washington, DC: The World Bank. https://doi.org/10.1596/978-1-4648-1096-1. 


\section{Figures}

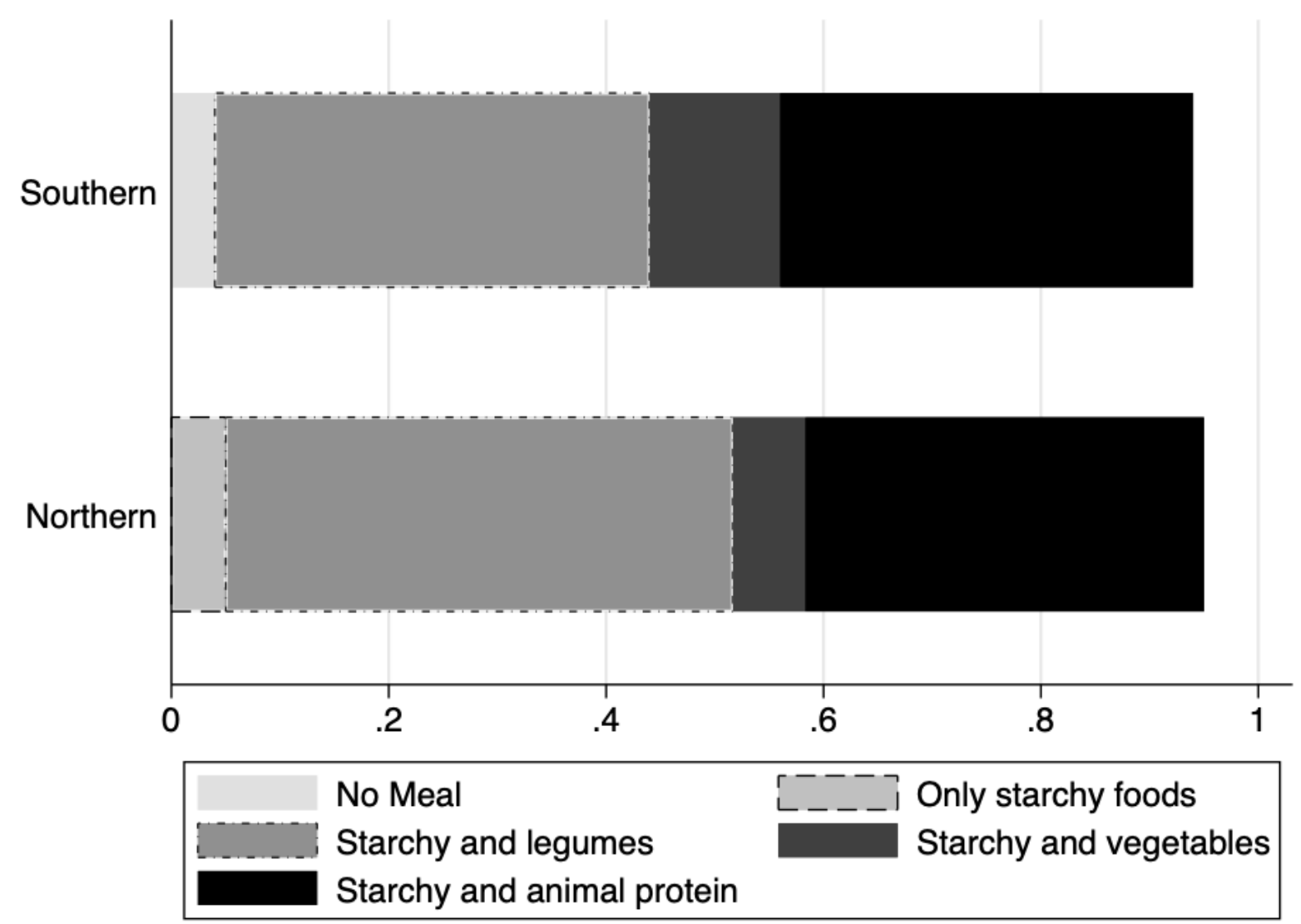

Figure 1.

Meal content by northern and southern regions

Notes: This figure presents the proportion of specific meal types served in the day of the interview and in the following day by region. Data on the meal served were taken by the caterer's weekly meal logs. Northern regions: Northern, Upper East and Upper West. Southern regions: Western, Central, Greater Accra, Volta, Eastern, Asanti, Brong Ahafo 


\section{Panel A. Raw test scores}

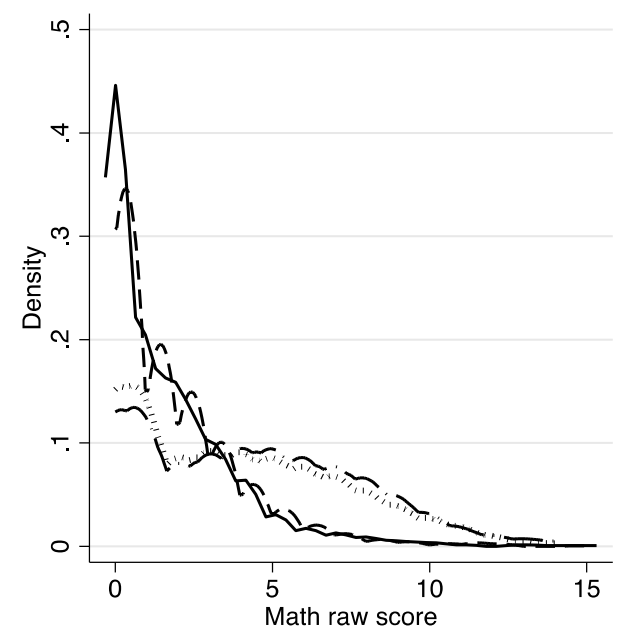

kernel $=$ epanechnikov, bandwidth $=0.3132$

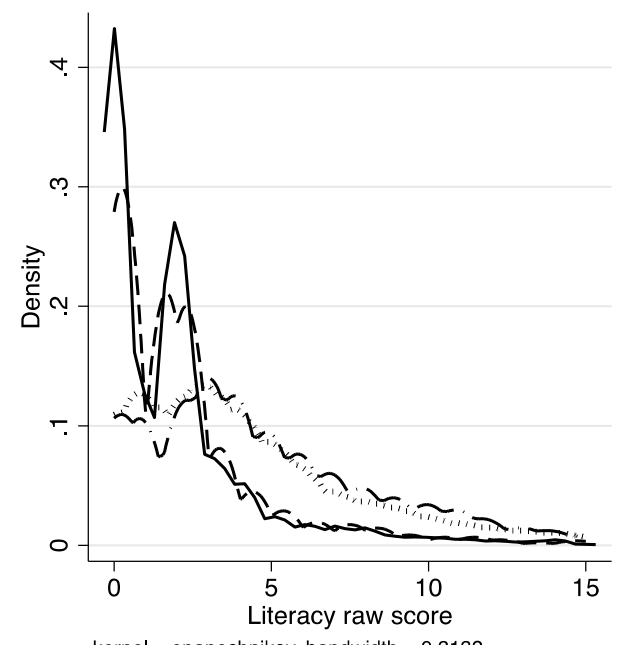

kernel $=$ epanechnikov, bandwidth $=0.3132$

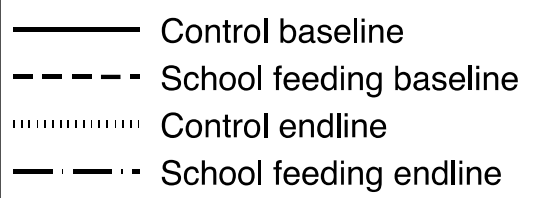

\section{Panel B. Age-standardized scores}
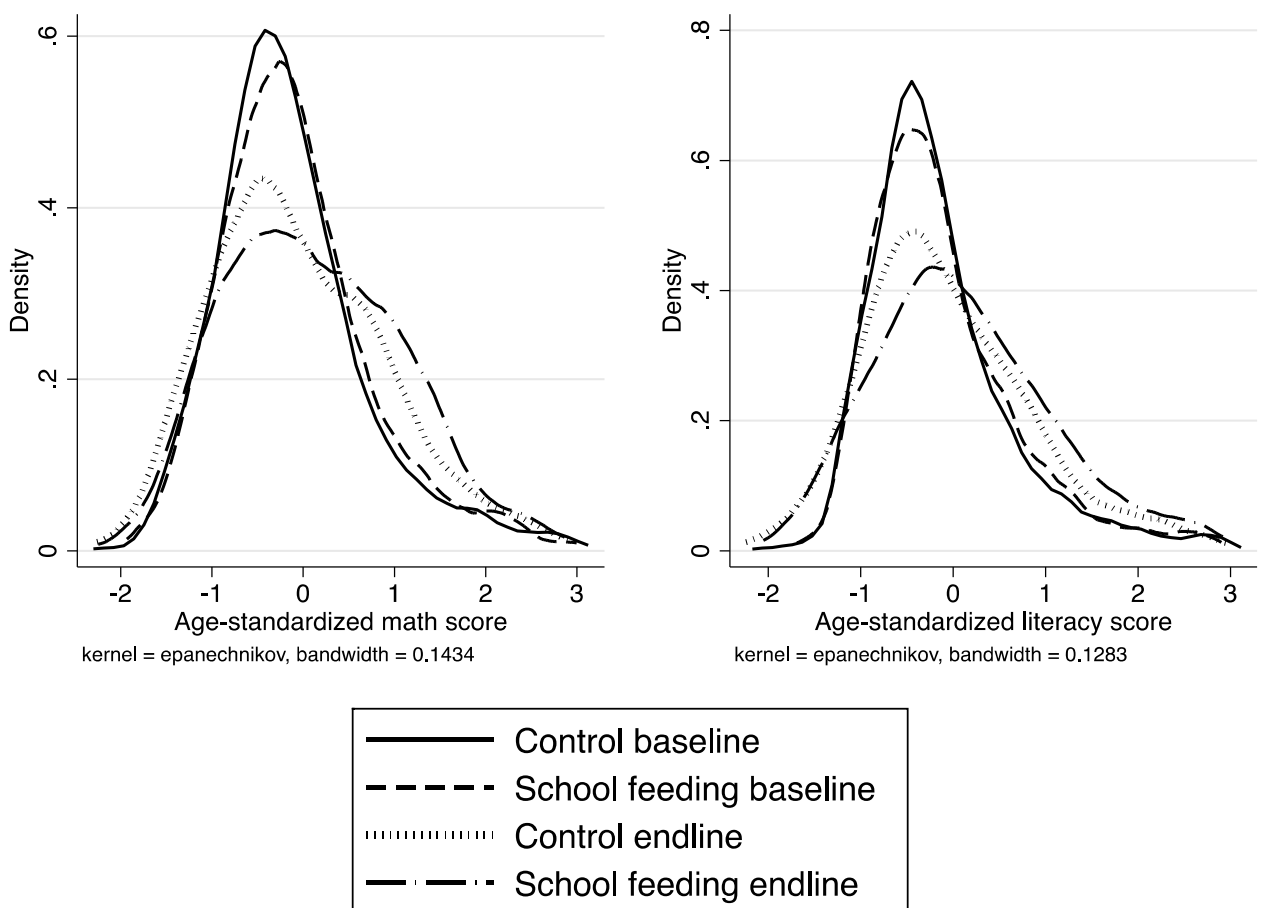

Figure 2. 
Empirical distributions of test scores for maths (left-side panel) and literacy (right-side panel), by survey round and treatment arm

Notes: This figure presents, by treatment group and survey wave, the non-parametric distributions of math (left-side panel) and literacy (right-side panel) scores for the full longitudinal sample of children. Panel A and B show raw and age-standardized test scores, respectively. Nonparametric distributions were calculated through weighted local polynomial regressions using an Epanechnikov kernel. 


\section{Panel A. Child Gender}
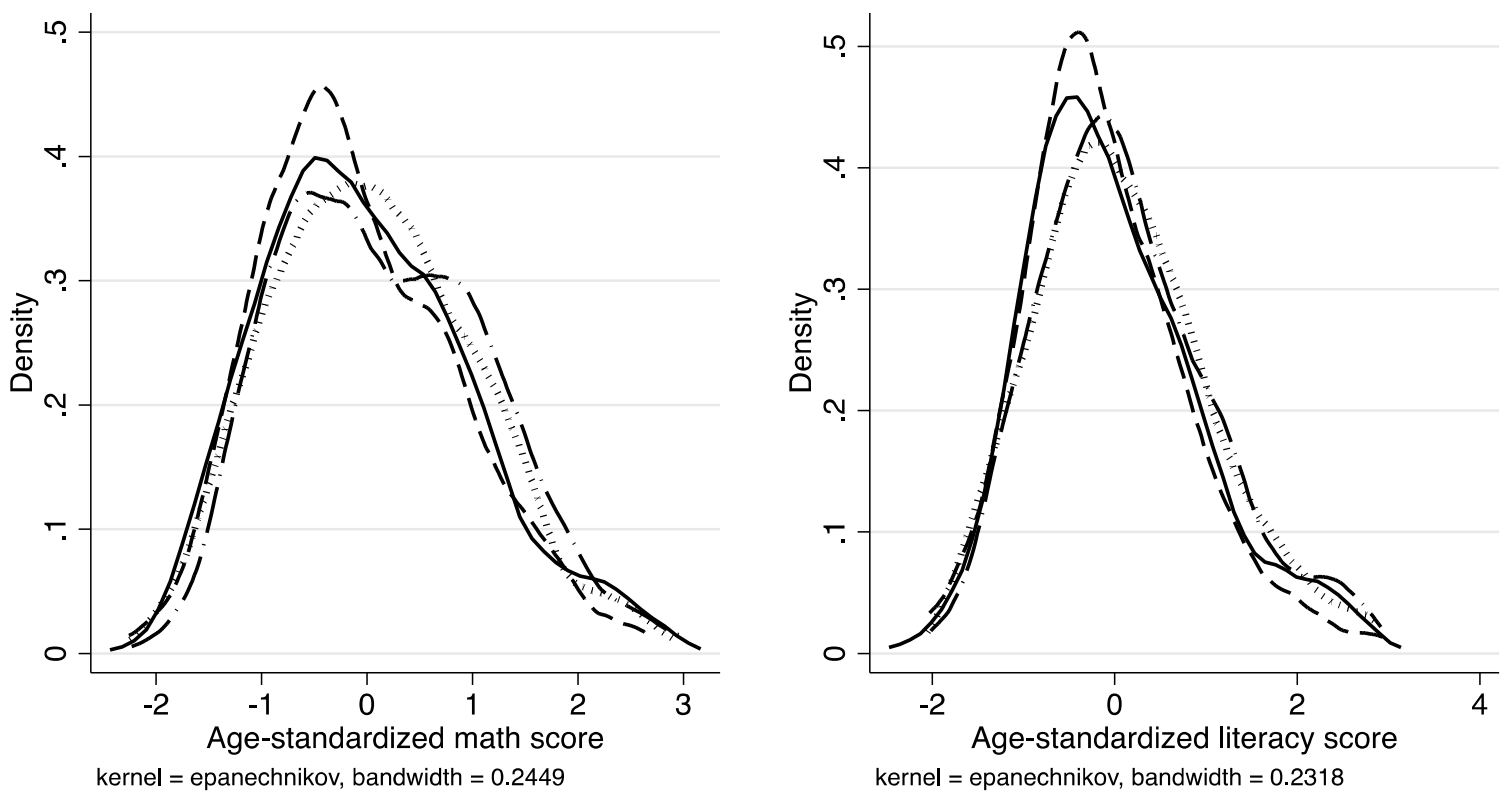

$$
\begin{array}{ll}
\hline- & \text { Control boys } \\
----- & \text { Control girls } \\
\ldots \ldots \ldots \ldots \ldots \ldots \ldots & \text { School feeding boys } \\
- \text { - - School feeding girls }
\end{array}
$$




\section{Panel B. Household poverty}
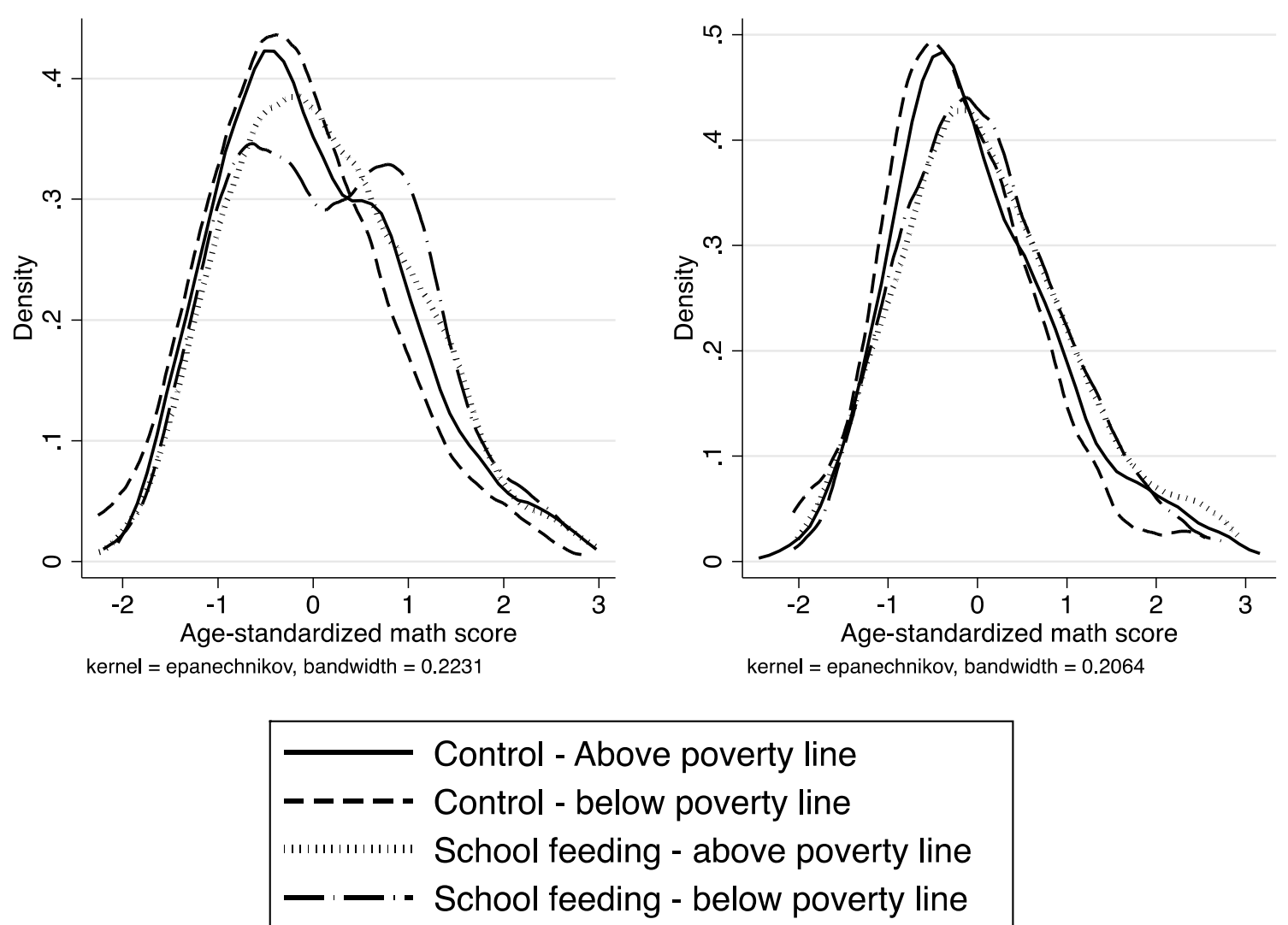


\section{Panel C. Geographical region}
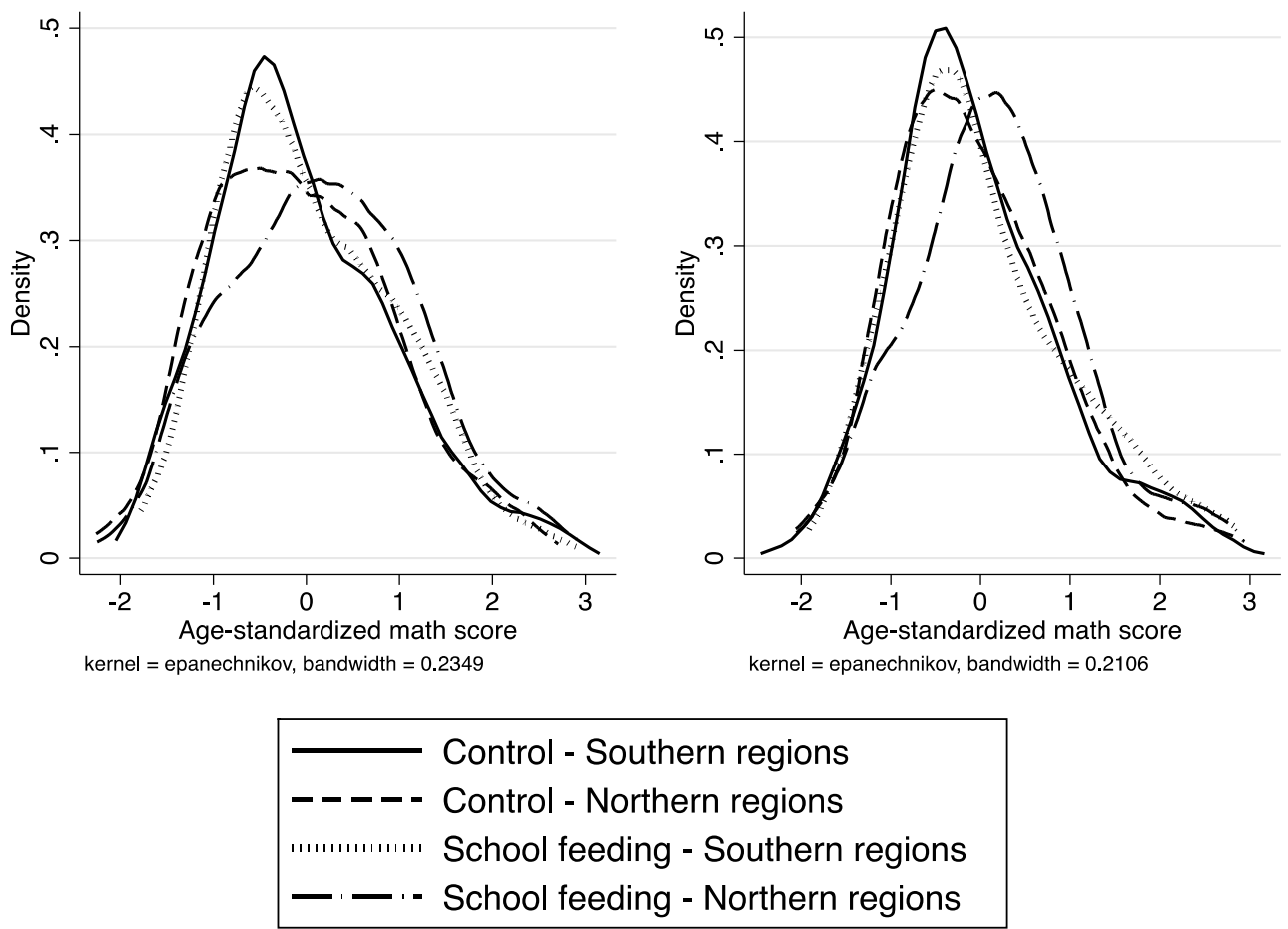

Figure 3.

Empirical endline distributions of age-standardised maths (left-side panel) and literacy (rightside panel) age-standardised test scores, by treatment arm and child gender, poverty and geographical region

Notes: These figures present endline age-standardized scores by treatment and gender (Panel A), household poverty status at baseline (Panel B) and geographical region (Panel C). Nonparametric distributions were calculated through weighted local polynomial regressions using an Epanechnikov kernel. Household poverty is a dichotomous indicator having the value of one if the household had baseline per capita consumption levels falling below the national consumption poverty line in 2013. Northern regions include Upper West, Upper East, and Northern region. Southern regions include Western, Central, Greater Accra, Volta, Eastern, Asanti, Brong Ahafo. 


\section{Tables}

Table 1.

Descriptive statistics and balance of covariates at baseline, full baseline sample

\begin{tabular}{|c|c|c|c|}
\hline & $\begin{array}{l}\text { Control } \\
(\mathrm{N}=1,612)\end{array}$ & $\begin{array}{c}\text { School feeding } \\
(\mathrm{N}=1,821)\end{array}$ & $\begin{array}{l}\text { School feeding - control } \\
\text { difference (SE) }\end{array}$ \\
\hline \multirow[t]{2}{*}{ Child age in months } & 102.73 & 103.92 & 1.185 \\
\hline & $(30.77)$ & $(31.45)$ & $(1.485)$ \\
\hline \multirow[t]{2}{*}{ Child is male } & 0.54 & 0.51 & -0.027 \\
\hline & $(0.50)$ & $(0.50)$ & $(0.018)$ \\
\hline \multirow[t]{2}{*}{ Enrolled } & 0.99 & 0.98 & -0.007 \\
\hline & $(0.11)$ & $(0.14)$ & $(0.006)$ \\
\hline \multirow{2}{*}{$\begin{array}{l}\text { Child has child fallen ill in last } 7 \\
\text { days }\end{array}$} & 0.10 & 0.09 & -0.010 \\
\hline & $(0.31)$ & $(0.29)$ & $(0.013)$ \\
\hline \multirow[t]{2}{*}{ Highest grade completed } & 1.67 & 1.76 & 0.088 \\
\hline & $(1.53)$ & $(1.48)$ & $(0.083)$ \\
\hline \multirow[t]{2}{*}{ Child has repeated a grade } & 0.11 & 0.12 & 0.011 \\
\hline & $(0.32)$ & $(0.33)$ & $(0.020)$ \\
\hline \multirow{2}{*}{$\begin{array}{l}\text { Absent from school in past } 7 \\
\text { days }\end{array}$} & 0.12 & 0.17 & 0.050 \\
\hline & $(0.66)$ & $(0.76)$ & $(0.041)$ \\
\hline \multirow[t]{2}{*}{ Private school } & 0.10 & 0.11 & 0.010 \\
\hline & $(0.30)$ & $(0.31)$ & $(0.033)$ \\
\hline \multirow[t]{2}{*}{ Height-for-age Z-scores } & -1.11 & -1.05 & 0.062 \\
\hline & $(1.35)$ & $(1.29)$ & $(0.088)$ \\
\hline \multirow[t]{2}{*}{ Number of children of target age } & 3.38 & 3.24 & -0.142 \\
\hline & (1.69) & $(1.71)$ & $(0.184)$ \\
\hline \multirow{2}{*}{$\begin{array}{l}\text { Number of children under } 5 \\
\text { years }\end{array}$} & 1.06 & 0.94 & -0.117 \\
\hline & $(0.94)$ & $(0.96)$ & $(0.092)$ \\
\hline \multirow[t]{2}{*}{ Household size } & 6.77 & 6.60 & -0.178 \\
\hline & $(2.72)$ & $(2.67)$ & $(0.313)$ \\
\hline \multirow[t]{2}{*}{ Head of the household is male } & 0.81 & 0.80 & -0.004 \\
\hline & $(0.39)$ & $(0.40)$ & $(0.040)$ \\
\hline \multirow[t]{2}{*}{ Head of the household's age } & 44.06 & 45.52 & $1.477^{*}$ \\
\hline & $(12.05)$ & (12.69) & $(0.742)$ \\
\hline \multirow{2}{*}{ Mother's age } & 37.45 & 38.58 & 1.128 \\
\hline & $(10.83)$ & $(10.95)$ & $(0.740)$ \\
\hline \multirow[t]{2}{*}{ Mother's education in years } & 5.22 & 6.01 & 0.789 \\
\hline & $(5.01)$ & $(4.17)$ & $(0.662)$ \\
\hline \multirow[t]{2}{*}{ Wealth index } & 13.21 & 13.38 & 0.174 \\
\hline & $(11.45)$ & $(11.77)$ & $(1.541)$ \\
\hline \multirow{2}{*}{$\begin{array}{l}\text { Sold agriculture produce in the } \\
\text { past year }\end{array}$} & 0.51 & 0.43 & -0.074 \\
\hline & $(0.50)$ & $(0.50)$ & $(0.055)$ \\
\hline \multirow[t]{2}{*}{ Per capita expenditure } & $2,085.17$ & 2092.62 & 7.446 \\
\hline & (993.87) & $(1,097.27)$ & $(109.181)$ \\
\hline \multirow[t]{2}{*}{ Household owns livestock } & 0.68 & 0.66 & -0.012 \\
\hline & $(0.47)$ & $(0.47)$ & $(0.048)$ \\
\hline \multirow[t]{2}{*}{ Urban } & 0.06 & 0.06 & 0.001 \\
\hline & $(0.24)$ & $(0.24)$ & $(0.039)$ \\
\hline \multirow[t]{2}{*}{ Northern regions } & 0.43 & 0.50 & 0.066 \\
\hline & $(0.50)$ & $(0.50)$ & $(0.110)$ \\
\hline
\end{tabular}

Notes: $* p<0.1 . N=3,433$. This table presents descriptive statistics for the full baseline sample of eligible children at baseline, stratified by assignment to treatment. The sample refers to all children aged 5-15 interviewed at baseline, prior to attrition. Mean and standard deviation in parentheses. The school feeding-control difference column reports the school feeding coefficient of a basic OLS regression with each covariate as an outcome and standard errors clustered at the community level. For each variable, the estimated school feeding coefficient provides the difference between the school feeding and control groups and its standard errors. 


\section{Table 2.}

Baseline correlates of children remaining in the longitudinal sample

\begin{tabular}{|c|c|c|c|}
\hline & (1) & (2) & (3) \\
\hline Treatment & $\begin{array}{l}-0.016 \\
(0.018)\end{array}$ & $\begin{array}{l}-0.016 \\
(0.019)\end{array}$ & $\begin{array}{l}-0.016 \\
(0.028)\end{array}$ \\
\hline Age-standardized maths score & & $\begin{array}{l}-0.000 \\
(0.010)\end{array}$ & \\
\hline Age-standardized literacy score & & $\begin{array}{c}0.011 \\
(0.010)\end{array}$ & \\
\hline Male & & & $\begin{array}{l}0.019 * \\
(0.012)\end{array}$ \\
\hline Male*Treatment & & & $\begin{array}{l}-0.013 \\
(0.018)\end{array}$ \\
\hline Northern regions & & & $\begin{array}{c}0.050 * * * \\
(0.017)\end{array}$ \\
\hline Northern regions* Treatment & & & $\begin{array}{l}-0.020 \\
(0.035)\end{array}$ \\
\hline Poor Household & & & $\begin{array}{l}-0.035 \\
(0.027)\end{array}$ \\
\hline Poor*Treatment & & & $\begin{array}{l}0.061 * \\
(0.036)\end{array}$ \\
\hline Constant & $\begin{array}{c}0.932 * * * \\
(0.010)\end{array}$ & $\begin{array}{c}0.933 * * * \\
(0.010)\end{array}$ & $\begin{array}{c}0.909 * * * \\
(0.014)\end{array}$ \\
\hline Observations & 3,433 & 3,158 & 3,432 \\
\hline R-squared & 0.001 & 0.002 & 0.009 \\
\hline Prob $>$ F & 0.388 & 0.400 & 0.012 \\
\hline
\end{tabular}

Notes: $* * * \mathrm{p}<0.01, * * \mathrm{p}<0.05, * \mathrm{p}<0.1$. This table presents probability of remaining in the longitudinal sample estimated through linear probability models, with standard errors clustered at the community level. $\mathrm{N}=3,433$ children of target-age prior to attrition. Lower sample sizes reflect covariates that are missing or not applicable. Column 1 shows probabilities of child being followed-up by treatment assignment; column 2 presents odd ratios by baseline learning and cognition, while column 3 interacts randomized assignment with key variables by which heterogeneity analysis was conducted throughout the paper. Household poverty is a dichotomous indicator having the value of one if the household had baseline per capita consumption levels falling below the national consumption poverty line in 2013. Northern regions include Upper West, Upper East, and Northern region. Southern regions include Western, Central, Greater Accra, Volta, Eastern, Asanti, Brong Ahafo. 
Table 3.

Descriptive statistics and test of balance of raw and age-standardized test scores, by survey round and treatment arm, longitudinal sample

\begin{tabular}{|c|c|c|c|c|c|}
\hline \multicolumn{4}{|c|}{ Baseline } & \multicolumn{2}{|l|}{ Endline } \\
\hline Contr & ol $(\mathrm{N}=1,404)$ & $\begin{array}{l}\text { School feeding } \\
(\mathrm{N}=1,579)\end{array}$ & $\begin{array}{l}\text { Treatment- } \\
\text { control } \\
\text { difference }(\mathrm{SE})^{\mathrm{a}}\end{array}$ & $\begin{array}{l}\text { Control } \\
(\mathrm{N}=1,186)\end{array}$ & $\begin{array}{l}\text { School feeding } \\
(\mathrm{N}=1,343)\end{array}$ \\
\hline \multirow[t]{2}{*}{ Math (raw score) } & 1.57 & 1.68 & 0.073 & 3.62 & 4.03 \\
\hline & $(2.04)$ & $(2.07)$ & $(0.146)$ & $(3.37)$ & $(3.43)$ \\
\hline \multirow[t]{2}{*}{ Math (age-standardized score) } & -0.13 & -0.09 & 0.051 & -0.04 & 0.11 \\
\hline & $(0.82)$ & $(0.83)$ & $(0.067)$ & $(0.96)$ & $(0.98)$ \\
\hline \multirow[t]{2}{*}{ Literacy (raw score) } & 1.81 & 1.97 & 0.106 & 3.87 & 4.33 \\
\hline & $(2.43)$ & $(2.56)$ & $(0.211)$ & $(3.51)$ & (3.57) \\
\hline \multirow{2}{*}{$\begin{array}{l}\text { Literacy (age-standardized } \\
\text { score) }\end{array}$} & -0.15 & -0.12 & 0.034 & -0.06 & 0.11 \\
\hline & $(0.77)$ & $(0.78)$ & $(0.067)$ & $(0.92)$ & $(0.97)$ \\
\hline
\end{tabular}

${ }^{a}$ The school feeding-control difference column reports the school feeding coefficient of a basic OLS regression of each outcome over school feeding arm and controlling for child age in months. Standard errors are clustered at the community level. Lower sample sizes in the cognitive scores (as compared to the full longitudinal sample) reflect missing values in those scores. 
Table 4a

Treatment effects estimated through ANCOVA: Full sample, and heterogeneity by child gender, household poverty, and geographical areas

\begin{tabular}{|c|c|c|c|c|c|c|}
\hline & \multicolumn{2}{|c|}{ Maths } & \multicolumn{2}{|c|}{ Literacy } & \multicolumn{2}{|c|}{ Composite learning score } \\
\hline \multicolumn{7}{|l|}{$\begin{array}{l}\text { Panel A. } \\
\text { All children }\end{array}$} \\
\hline School feeding & \multicolumn{2}{|c|}{0.147} & \multicolumn{2}{|c|}{0.132} & \multicolumn{2}{|c|}{$\begin{array}{c}0.168 \\
{[0.002-0.333]}\end{array}$} \\
\hline Unadjusted p-value & \multicolumn{2}{|c|}{$0.055^{*}$} & \multicolumn{2}{|c|}{$0.072 *$} & \multicolumn{2}{|c|}{$0.047 * *$} \\
\hline R-W p-value & \multicolumn{2}{|c|}{$0.098^{*}$} & \multicolumn{2}{|c|}{$0.098^{*}$} & & \\
\hline Observations & \multicolumn{2}{|c|}{2,278} & \multicolumn{2}{|c|}{2,274} & \multicolumn{2}{|c|}{2,314} \\
\hline $\begin{array}{l}\text { R-squared } \\
\text { Mean Treatment }\end{array}$ & \multicolumn{2}{|c|}{0.068} & \multicolumn{2}{|c|}{0.130} & \multicolumn{2}{|c|}{0.139} \\
\hline $\begin{array}{l}\text { Endline } \\
\text { Mean Control }\end{array}$ & \multicolumn{2}{|c|}{0.112} & \multicolumn{2}{|c|}{0.105} & \multicolumn{2}{|c|}{0.194} \\
\hline Endline & \multicolumn{2}{|c|}{-0.0435} & \multicolumn{2}{|c|}{-0.0562} & \multicolumn{2}{|c|}{0} \\
\hline & \multicolumn{2}{|c|}{ Maths } & \multicolumn{2}{|c|}{ Literacy } & \multicolumn{2}{|c|}{ Composite learning score } \\
\hline $\begin{array}{l}\text { Panel B: } \\
\text { Gender }\end{array}$ & Girls & Boys & Girls & Boys & Girls & Boys \\
\hline School feeding & $\begin{array}{c}0.242 \\
{[0.079-} \\
0.405]\end{array}$ & $\begin{array}{c}0.0645 \\
{[-0.116-} \\
0.245]\end{array}$ & $\begin{array}{c}0.205 \\
{[0.042-} \\
0.368]\end{array}$ & $\begin{array}{c}0.0758 \\
{[-0.084-} \\
0.235]\end{array}$ & $\begin{array}{c}0.273 \\
{[0.0887-} \\
0.456]\end{array}$ & $\begin{array}{c}0.0797 \\
{[-0.107-} \\
0.267]\end{array}$ \\
\hline Unadjusted p-value & $0.004 * * *$ & 0.478 & $0.014 * *$ & 0.349 & $0.004 * * *$ & 0.399 \\
\hline R-W p-value & $0.006^{* * *}$ & 0.573 & $0.012 * *$ & 0.573 & & \\
\hline Observations & 1,071 & 1,207 & 1,067 & 1,207 & 1,085 & 1,229 \\
\hline $\begin{array}{l}\text { R-squared } \\
\text { Mean Treatment }\end{array}$ & 0.089 & 0.062 & 0.137 & 0.135 & 0.150 & 0.144 \\
\hline $\begin{array}{l}\text { Endline } \\
\text { Mean Control }\end{array}$ & 0.158 & 0.0700 & 0.120 & 0.0923 & 0.237 & 0.156 \\
\hline Endline & -0.0878 & -0.00534 & -0.102 & -0.0170 & -0.0509 & 0.0440 \\
\hline
\end{tabular}


Table 4a (ctd.)

\begin{tabular}{|c|c|c|c|c|c|c|}
\hline \multirow[b]{2}{*}{$\begin{array}{l}\text { Panel C: } \\
\text { Household Poverty }\end{array}$} & \multicolumn{2}{|c|}{ Maths } & \multicolumn{2}{|c|}{ Literacy } & \multicolumn{2}{|c|}{$\begin{array}{c}\text { Composite learning } \\
\text { score }\end{array}$} \\
\hline & $\begin{array}{l}\text { Below the } \\
\text { poverty line }\end{array}$ & Non-poor & $\begin{array}{c}\text { Below the } \\
\text { poverty } \\
\text { line }\end{array}$ & Non-poor & $\begin{array}{c}\text { Below the } \\
\text { poverty } \\
\text { line }\end{array}$ & Non-poor \\
\hline School feeding & $\begin{array}{c}0.309 \\
{[0.099-} \\
0.519]\end{array}$ & $\begin{array}{c}0.101 \\
{[-0.0642-} \\
0.267]\end{array}$ & $\begin{array}{c}0.233 \\
{[0.037-} \\
0.428]\end{array}$ & $\begin{array}{c}0.0883 \\
{[-0.0755-} \\
0.252]\end{array}$ & $\begin{array}{c}0.328 \\
{[0.114-} \\
0.542]\end{array}$ & $\begin{array}{c}0.114 \\
{[-0.072-} \\
0.299]\end{array}$ \\
\hline Unadjusted p-value & $0.004 * * *$ & 0.227 & $0.02 * *$ & 0.287 & $0.003 * * *$ & 0.227 \\
\hline R-W p-value & $0.008 * * *$ & 0.403 & $0.022 * *$ & 0.403 & & \\
\hline Observations & 539 & 1,739 & 537 & 1,737 & 542 & 1,772 \\
\hline $\begin{array}{l}\text { R-squared } \\
\text { Mean Treatment }\end{array}$ & 0.090 & 0.071 & 0.089 & 0.151 & 0.123 & 0.151 \\
\hline $\begin{array}{l}\text { Endline } \\
\text { Mean Control }\end{array}$ & 0.136 & 0.104 & 0.0704 & 0.116 & 0.177 & 0.199 \\
\hline Endline & -0.186 & $-5.20 \mathrm{e}-05$ & -0.203 & -0.0115 & -0.177 & 0.0539 \\
\hline & & & & & $\begin{array}{r}\text { Compos } \\
\text { s }\end{array}$ & $\begin{array}{l}\text { learning } \\
\text { e }\end{array}$ \\
\hline
\end{tabular}

\begin{tabular}{lcccccc} 
Panel D: & & & & & \\
Place of residence & North & South & North & South & North & South \\
\cline { 2 - 6 } & & & & & & \\
School feeding & 0.253 & 0.0508 & 0.243 & 0.0308 & 0.297 & 0.0496 \\
& {$[-0.005-$} & {$[-0.118-$} & {$[0.012-$} & {$[-0.148-$} & {$[0.023-$} & {$[-0.146-$} \\
& $0.511]$ & $0.220]$ & $0.474]$ & $0.209]$ & $0.570]$ & $0.245]$ \\
Unadjusted p-value & $0.054^{*}$ & 0.549 & $0.04^{* *}$ & 0.731 & $0.034^{* *}$ & 0.613 \\
R-W p-value & $0.061^{*}$ & 0.797 & $0.062^{*}$ & 0.797 & & \\
& & & & & & \\
Observations & 1,083 & 1,195 & 1,087 & 1,187 & 1,096 & 1,218 \\
$\begin{array}{l}\text { R-squared } \\
\text { Mean Treatment }\end{array}$ & 0.043 & 0.099 & 0.098 & 0.163 & 0.090 & 0.193 \\
$\begin{array}{l}\text { Endline } \\
\text { Mean Control }\end{array}$ & 0.179 & 0.0418 & 0.169 & 0.0382 & 0.270 & 0.115 \\
Endline & & & & & & \\
\hline
\end{tabular}

Notes: $* * * \mathrm{p}<0.01, * * \mathrm{p}<0.05, * \mathrm{p}<0.1$. Confidence intervals clustered at community level in squared brackets. R-W p-values were adjusted for multiple testing using the Romano-Wolf $(2005,2016)$ step-down method with 2,000 iterations and standard errors clustered at community level.

The table above presents intent-to-treat effects on each outcome estimated through ANCOVA for the full sample and stratified by child gender, household poverty, and place of residence. Models were estimated through OLS. For each outcome, the model controls for its baseline value, a dichotomous variable related to the randomized assignment to school feeding, and region dummies. Math and literacy scores are age-standardized. The composite index of learning was computed as the average of the math and literacy scores and then they were standardized to the control group within each round. Household poverty is a dichotomous indicator having the value of one if the household had baseline per capita consumption levels falling below the national consumption poverty line in 2013 . Northern regions include 
Upper West, Upper East, and Northern region. Southern regions include Western, Central, Greater Accra, Volta, Eastern, Asanti, Brong Ahafo. 
Table $4 \mathrm{~b}$

Treatment effects estimated through difference-in-differences: Full sample and heterogeneity by child gender, household poverty, and geographical areas

\section{Maths}

\begin{tabular}{|c|c|c|c|c|c|c|}
\hline & \multicolumn{2}{|c|}{ viatns } & \multicolumn{2}{|c|}{ Literacy } & \multicolumn{2}{|c|}{ score } \\
\hline \multicolumn{7}{|l|}{ Panel A. All children } \\
\hline School feeding & \multicolumn{2}{|c|}{0.114} & \multicolumn{2}{|c|}{0.139} & \multicolumn{2}{|c|}{0.149} \\
\hline & \multicolumn{2}{|c|}{$[-0.061-0.289]$} & \multicolumn{2}{|c|}{$[-0.027-0.306]$} & \multicolumn{2}{|c|}{$[-0.056-0.353]$} \\
\hline Unadjusted p-value & \multicolumn{2}{|c|}{0.199} & \multicolumn{2}{|c|}{$0.100 *$} & \multicolumn{2}{|c|}{0.152} \\
\hline R-W p-value & \multicolumn{2}{|c|}{0.197} & \multicolumn{2}{|c|}{0.166} & & \\
\hline Observations & \multicolumn{2}{|c|}{5,369} & \multicolumn{2}{|c|}{5360} & \multicolumn{2}{|c|}{5,411} \\
\hline R-squared & \multirow{2}{*}{\multicolumn{2}{|c|}{0.031}} & \multirow{2}{*}{\multicolumn{2}{|c|}{0.042}} & \multicolumn{2}{|c|}{0.043} \\
\hline Mean Treatment & & & & & & \\
\hline Endline & \multicolumn{2}{|c|}{0.112} & \multicolumn{2}{|c|}{0.105} & \multicolumn{2}{|c|}{0.194} \\
\hline \multirow[t]{2}{*}{ Mean Control Endline } & \multicolumn{2}{|c|}{-0.0435} & \multicolumn{2}{|c|}{-0.0562} & \multicolumn{2}{|c|}{0} \\
\hline & \multicolumn{2}{|c|}{ Maths } & \multicolumn{2}{|c|}{ Literacy } & \multicolumn{2}{|c|}{$\begin{array}{c}\text { Composite learning } \\
\text { score } \\
\end{array}$} \\
\hline Panel B: Gender & Girls & Boys & Girls & Boys & Girls & Boys \\
\hline School feeding & $\begin{array}{c}0.204 \\
{[0.012-} \\
0.397]\end{array}$ & $\begin{array}{c}0.0373 \\
{[-0.174-} \\
0.248]\end{array}$ & $\begin{array}{c}0.192 \\
{[0.008-} \\
0.377]\end{array}$ & $\begin{array}{c}0.0983 \\
{[-0.091-} \\
0.288]\end{array}$ & $\begin{array}{c}0.239 \\
0.013- \\
0.466\end{array}$ & $\begin{array}{c}0.0738 \\
{[-0.160-} \\
0.307]\end{array}$ \\
\hline Unadjusted p-value & $0.038 * *$ & 0.726 & $0.041 * *$ & 0.306 & $0.039 * *$ & 0.532 \\
\hline R-W p-value & $0.063 *$ & 0.713 & 0.0625 & 0.466 & & \\
\hline Observations & 2,540 & 2,829 & 2,534 & 2,826 & 2,558 & 2,853 \\
\hline $\begin{array}{l}\text { R-squared } \\
\text { Mean Treatment }\end{array}$ & 0.037 & 0.032 & 0.036 & 0.052 & 0.041 & 0.050 \\
\hline Endline & 0.158 & 0.0700 & 0.120 & 0.0923 & 0.237 & 0.156 \\
\hline Mean Control Endline & -0.0878 & -0.00534 & -0.102 & -0.0170 & -0.0509 & 0.0440 \\
\hline
\end{tabular}

Composite learning 
Table $4 \mathrm{~b}$ (ctd.)

\begin{tabular}{|c|c|c|c|c|c|c|}
\hline $\begin{array}{l}\text { Panel C: Household } \\
\text { Poverty }\end{array}$ & $\begin{array}{l}\text { Below the } \\
\text { poverty line }\end{array}$ & Non-poor & $\begin{array}{l}\text { Below the } \\
\text { poverty line }\end{array}$ & Non-poor & $\begin{array}{l}\text { Below the } \\
\text { poverty line }\end{array}$ & Non-poor \\
\hline School feeding & $\begin{array}{c}0.270 \\
{[0.021-} \\
0.519]\end{array}$ & $\begin{array}{c}0.0677 \\
{[-0.118-} \\
0.254]\end{array}$ & $\begin{array}{c}0.335 \\
{[0.140-} \\
0.529]\end{array}$ & $\begin{array}{c}0.0798 \\
{[-0.112-} \\
0.272]\end{array}$ & $\begin{array}{c}0.346 \\
{[0.099-} \\
0.593]\end{array}$ & $\begin{array}{c}0.0894 \\
{[-0.136-} \\
0.315]\end{array}$ \\
\hline Unadjusted p-value & $0.034 * *$ & 0.471 & $0.001 * * *$ & 0.411 & $0.007 * * *$ & 0.432 \\
\hline R-W p-value & $0.036^{* *}$ & 0.608 & $0.001 * * *$ & 0.608 & & \\
\hline Observations & 1,243 & 4,125 & 1,241 & 4,118 & 1,247 & 4,163 \\
\hline $\begin{array}{l}\text { R-squared } \\
\text { Mean Treatment }\end{array}$ & 0.062 & 0.028 & 0.065 & 0.039 & 0.060 & 0.041 \\
\hline $\begin{array}{l}\text { Endline } \\
\text { Mean Control }\end{array}$ & 0.136 & 0.104 & 0.0704 & 0.116 & 0.177 & 0.199 \\
\hline Endline & -0.186 & $-5.20 \mathrm{e}-05$ & -0.203 & -0.0115 & -0.177 & 0.0539 \\
\hline & \multicolumn{2}{|c|}{ Maths } & \multicolumn{2}{|c|}{ Literacy } & \multicolumn{2}{|c|}{ Composite learning score } \\
\hline $\begin{array}{l}\text { Panel D: } \\
\text { Place of residence }\end{array}$ & North & South & North & South & North & South \\
\hline School feeding & $\begin{array}{c}0.204 \\
{[-0.073-} \\
0.480]\end{array}$ & $\begin{array}{c}0.0125 \\
{[-0.210-} \\
0.235]\end{array}$ & $\begin{array}{c}0.204 \\
{[-0.035-} \\
0.442]\end{array}$ & $\begin{array}{c}0.0547 \\
{[-0.159-} \\
0.269]\end{array}$ & $\begin{array}{c}0.244 \\
{[-0.047-} \\
0.536]\end{array}$ & $\begin{array}{c}0.0305 \\
{[-0.238-} \\
0.299]\end{array}$ \\
\hline Unadjusted p-value & 0.144 & 0.911 & $0.092 *$ & 0.610 & $0.098^{*}$ & 0.821 \\
\hline R-W p-value & 0.139 & 0.896 & 0.139 & 0.800 & & \\
\hline Observations & 2,503 & 2,866 & 2,509 & 2,851 & 2,519 & 2,892 \\
\hline $\begin{array}{l}\text { R-squared } \\
\text { Mean Treatment }\end{array}$ & 0.033 & 0.035 & 0.046 & 0.047 & 0.030 & 0.059 \\
\hline $\begin{array}{l}\text { Endline } \\
\text { Mean Control }\end{array}$ & 0.179 & 0.0418 & 0.169 & 0.0382 & 0.270 & 0.115 \\
\hline Endline & -0.0639 & -0.0273 & -0.0629 & -0.0509 & -0.0160 & 0.0127 \\
\hline
\end{tabular}

Notes: $* * * \mathrm{p}<0.01, * * \mathrm{p}<0.05, * \mathrm{p}<0.1$. Confidence intervals clustered at community level in squared brackets. R-W p-values were adjusted for multiple testing using the Romano-Wolf $(2005,2016)$ step-down method with 2,000 iterations and standard errors clustered at community level.

The table above presents intent-to-treat effects on each outcome estimated through difference-in-differences for the full sample and stratified by child gender, household poverty, and place of residence. Models were estimated through OLS. Models include a dichotomous variable for treatment assignment, a dummy for endline survey, and the treatment effect relates to the interaction between these two variables. It also includes region dummies. Math and literacy scores are age-standardized. Composite indices were computed as averages of the standardized scores and then they were standardized to the control group within each round. Household poverty is a dichotomous indicator having the value of one if the household had baseline per capita consumption levels falling below the national consumption poverty line in 2013. Northern regions include Upper West, Upper East, and Northern region. Southern regions include 
Western, Central, Greater Accra, Volta, Eastern, Asanti, Brong Ahafo. 
Table 5.

Treatment effects of school feeding on schooling estimated through ANCOVA, full sample, and heterogeneity by child gender, household poverty, and geographical areas

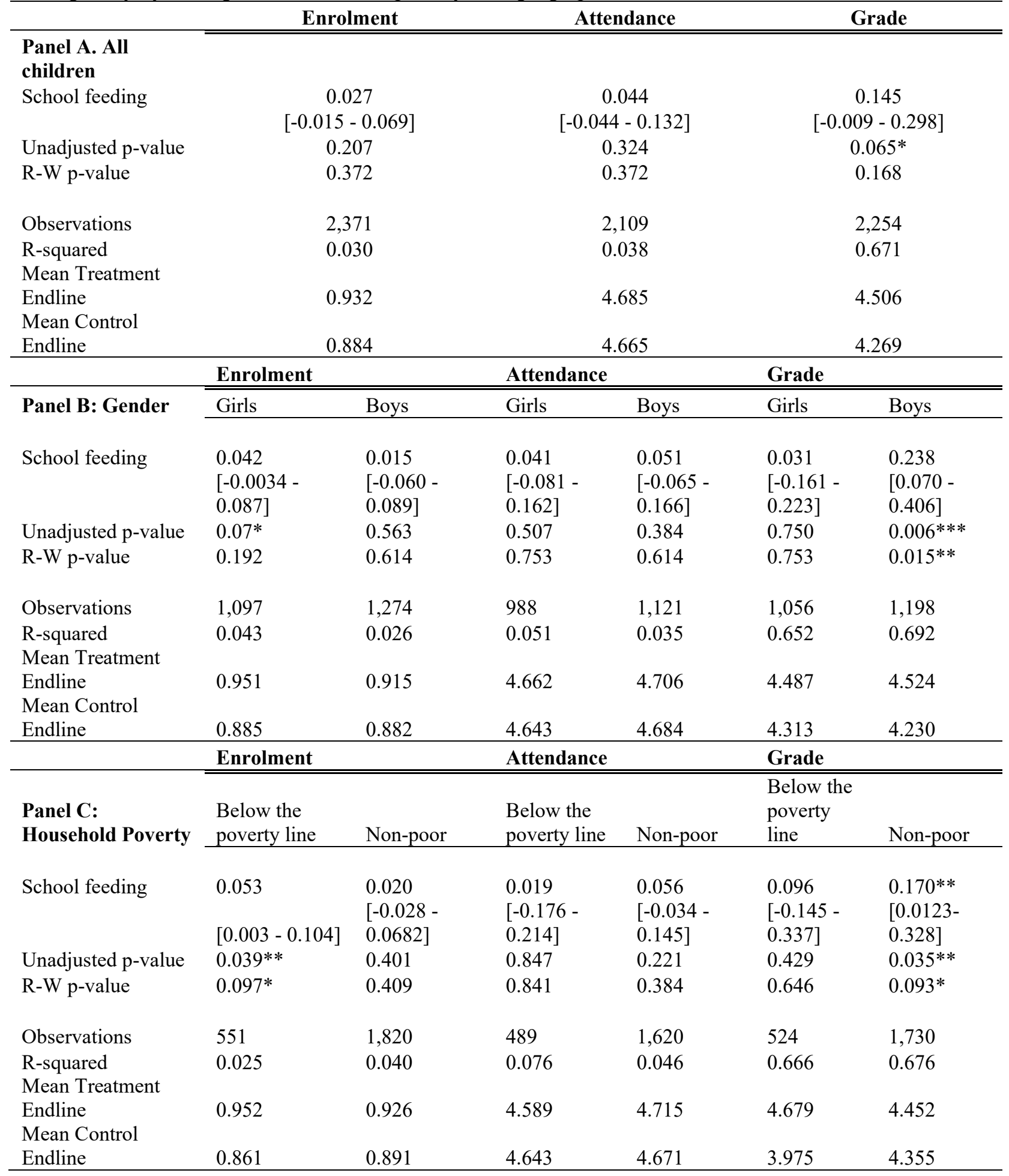


Table 5 (ctd.)

\begin{tabular}{lllllll}
\hline & \multicolumn{2}{l}{ Enrolment } & \multicolumn{3}{c}{ Attendance } & Grade \\
\cline { 2 - 6 } $\begin{array}{l}\text { Panel D: } \\
\text { Place of residence }\end{array}$ & & & & & \\
& North & South & North & South & North & South \\
\cline { 2 - 6 } School feeding & & & & & & \\
& 0.076 & -0.013 & 0.072 & 0.020 & 0.223 & 0.0781 \\
& {$[0.016-$} & {$[-0.067-$} & {$[-0.026-$} & {$[-0.122-$} & {$[-0.042-$} & {$[-0.102-$} \\
Unadjusted p-value & $0.135]$ & $0.0405]$ & $0.171]$ & $0.162]$ & $0.489]$ & $0.258]$ \\
R-W p-value & $0.014^{* *}$ & 0.624 & 0.146 & 0.778 & $0.097^{*}$ & 0.387 \\
& $0.033^{* *}$ & 0.864 & 0.170 & 0.864 & 0.170 & 0.778 \\
Observations & & & & & & \\
R-squared & 1,092 & 1,279 & 992 & 1,117 & 1,030 & 1,224 \\
$\begin{array}{l}\text { Mean Treatment } \\
\text { Endline }\end{array}$ & 0.051 & 0.026 & 0.005 & 0.034 & 0.639 & 0.695 \\
$\begin{array}{l}\text { Mean Control } \\
\text { Endline }\end{array}$ & 0.932 & 0.932 & 4.820 & 4.545 & 4.352 & 4.667 \\
\hline
\end{tabular}

Notes: $* * * \mathrm{p}<0.01, * * \mathrm{p}<0.05, * \mathrm{p}<0.1$. Confidence intervals clustered at community levels in squared brackets. R-W p-values were adjusted for multiple testing using the Romano-Wolf $(2005,2016)$ step-down method with 2,000 iterations and standard errors clustered at community level.

The table above presents intent-to-treat effects on each outcome for the full sample and stratified by child gender, household poverty, and place of residence. Models were estimated through OLS. For each outcome, the model controls for its baseline value, a dichotomous variable related to the randomized assignment to school feeding, and region dummies. Enrolment is a dichotomous variable indicating whether the child is enrolled to any level of education; attendance is an indicator counting the number of days the child attended by the child in the past school week. The indicator ranges from 0 to 5 days. Current grade provides the educational grade (in years) the child is currently enrolled in. Household poverty is a dichotomous indicator having the value of one if the household had baseline per capita consumption levels falling below the national consumption poverty line in 2013. Northern regions include Upper West, Upper East, and Northern region. Southern regions include Western, Central, Greater Accra, Volta, Eastern, Asanti, Brong Ahafo. 
Table 6.

Treatment effects of school feeding on child cognitive scores, full sample, and heterogeneity by child gender, household poverty, and geographical areas

\begin{tabular}{|c|c|c|c|c|c|c|}
\hline & \multicolumn{2}{|c|}{ Digit Span } & \multicolumn{2}{|c|}{$\begin{array}{l}\text { Standardized progressive } \\
\text { matrices }\end{array}$} & \multicolumn{2}{|c|}{ Composite cognitive score } \\
\hline \multicolumn{7}{|l|}{$\begin{array}{l}\text { Panel A. All } \\
\text { children }\end{array}$} \\
\hline School feeding & \multirow{2}{*}{\multicolumn{2}{|c|}{$\begin{array}{c}0.119 \\
{[-0.010-0.249]}\end{array}$}} & \multirow{2}{*}{\multicolumn{2}{|c|}{$\begin{array}{c}0.129 \\
{[0.018-0.240]}\end{array}$}} & \multirow{2}{*}{\multicolumn{2}{|c|}{$\begin{array}{c}0.143 \\
{[0.019-0.267]}\end{array}$}} \\
\hline & & & & & & \\
\hline Unadjusted $\mathrm{p}$-value & \multicolumn{2}{|c|}{$0.070 *$} & \multicolumn{2}{|c|}{$0.024 * *$} & \multicolumn{2}{|c|}{$0.024 * *$} \\
\hline R-W p-value & \multicolumn{2}{|c|}{$0.070^{*}$} & \multicolumn{2}{|c|}{$0.046^{* *}$} & & \\
\hline Observations & \multicolumn{2}{|c|}{2,305} & \multicolumn{2}{|c|}{2,307} & \multicolumn{2}{|c|}{2,321} \\
\hline $\begin{array}{l}\text { R-squared } \\
\text { Mean Treatment }\end{array}$ & \multicolumn{2}{|c|}{0.050} & \multicolumn{2}{|c|}{0.034} & \multicolumn{2}{|c|}{0.064} \\
\hline Endline & \multirow{2}{*}{\multicolumn{2}{|c|}{0.0992}} & \multirow{2}{*}{\multicolumn{2}{|c|}{0.119}} & \multirow{2}{*}{\multicolumn{2}{|c|}{0.171}} \\
\hline Mean Control & & & & & & \\
\hline Endline & \multicolumn{2}{|c|}{-0.0348} & \multicolumn{2}{|c|}{-0.0326} & \multicolumn{2}{|c|}{0} \\
\hline & \multicolumn{2}{|c|}{ Digit Span } & \multicolumn{2}{|c|}{$\begin{array}{l}\text { Standardized progressive } \\
\text { matrices }\end{array}$} & \multicolumn{2}{|c|}{ Composite cognitive score } \\
\hline Panel B: Gender & Girls & Boys & Girls & Boys & Girls & Boys \\
\hline School feeding & $\begin{array}{l}0.190 \\
{[0.0372-} \\
0.342]\end{array}$ & $\begin{array}{l}0.0649 \\
{[-0.207-} \\
0.336]\end{array}$ & $\begin{array}{l}0.116 \\
{[-0.0358-} \\
0.267]\end{array}$ & $\begin{array}{l}0.148 \\
{[0.0191-} \\
0.276]\end{array}$ & $\begin{array}{l}0.175 \\
{[0.0215-} \\
0.329]\end{array}$ & $\begin{array}{l}0.124 \\
{[-0.0223-} \\
0.271]\end{array}$ \\
\hline Unadjusted $\mathrm{p}$-value & $0.015^{* *}$ & 0.404 & 0.133 & $0.025^{* *}$ & $0.026^{* *}$ & $0.01 *$ \\
\hline R-W p-value & $0.032 * *$ & 0.403 & 0.122 & $0.042 * *$ & & \\
\hline Observations & 1,085 & 1,220 & 1,086 & 1,221 & 1,091 & 1,230 \\
\hline $\begin{array}{l}\text { R-squared } \\
\text { Mean Treatment }\end{array}$ & 0.057 & 0.053 & 0.043 & 0.037 & 0.071 & 0.068 \\
\hline $\begin{array}{l}\text { Endline } \\
\text { Mean Control }\end{array}$ & 0.0977 & 0.101 & 0.0687 & 0.165 & 0.140 & 0.200 \\
\hline Endline & 0.108 & 0.0288 & -0.0942 & 0.0208 & -0.0828 & 0.0717 \\
\hline
\end{tabular}


Table 6 (ctd.)

\begin{tabular}{|c|c|c|c|c|c|c|}
\hline & \multicolumn{2}{|l|}{ Digit Span } & \multicolumn{2}{|c|}{$\begin{array}{l}\text { Standardized progressive } \\
\text { matrices }\end{array}$} & \multicolumn{2}{|c|}{ Composite cognitive score } \\
\hline $\begin{array}{l}\text { Panel C: } \\
\text { Household Poverty }\end{array}$ & $\begin{array}{l}\text { Below the } \\
\text { poverty line }\end{array}$ & Non-poor & $\begin{array}{l}\text { Below the } \\
\text { poverty line }\end{array}$ & Non-poor & $\begin{array}{l}\text { Below the } \\
\text { poverty line }\end{array}$ & Non-poor \\
\hline School feeding & $\begin{array}{l}0.269 \\
{[0.108-} \\
0.429]\end{array}$ & $\begin{array}{l}0.0723 \\
{[-0.172-} \\
0.316]\end{array}$ & $\begin{array}{l}0.234 \\
{[0.100-} \\
0.367]\end{array}$ & $\begin{array}{l}0.0931 \\
{[-0.0427-} \\
0.229]\end{array}$ & $\begin{array}{l}0.293 \\
{[0.147-} \\
0.440]\end{array}$ & $\begin{array}{l}0.0946 \\
{[-0.0517-} \\
0.241]\end{array}$ \\
\hline Unadjusted p-value & $0.001 * * *$ & 0.339 & $0.001 * * *$ & 0.177 & $0.0002 * * *$ & 0.202 \\
\hline R-W p-value & $0.002 * * *$ & 0.342 & $0.002 * * *$ & 0.309 & & \\
\hline Observations & 540 & 1,765 & 537 & 1,770 & 542 & 1,779 \\
\hline $\begin{array}{l}\text { R-squared } \\
\text { Mean Treatment }\end{array}$ & 0.096 & 0.042 & 0.071 & 0.030 & 0.112 & 0.056 \\
\hline $\begin{array}{l}\text { Endline } \\
\text { Mean Control }\end{array}$ & 0.127 & 0.0907 & 0.138 & 0.113 & 0.196 & 0.164 \\
\hline \multirow[t]{2}{*}{ Endline } & -0.207 & 0.0175 & -0.161 & 0.00626 & -0.180 & 0.0547 \\
\hline & \multicolumn{2}{|l|}{ Digit Span } & \multicolumn{2}{|c|}{$\begin{array}{l}\text { Standardized progressive } \\
\text { matrices }\end{array}$} & \multicolumn{2}{|c|}{ Composite cognitive score } \\
\hline $\begin{array}{l}\text { Panel D: } \\
\text { Place of residence }\end{array}$ & North & South & North & South & North & South \\
\hline School feeding & $\begin{array}{l}0.253 \\
{[0.0798-} \\
0.427]\end{array}$ & $\begin{array}{l}-0.002 \\
{[-0.323-} \\
0.318]\end{array}$ & $\begin{array}{l}0.212 \\
{[0.040-} \\
0.384]\end{array}$ & $\begin{array}{l}0.051 \\
{[-0.0922-} \\
0.194]\end{array}$ & $\begin{array}{l}0.272 \\
{[0.0994-} \\
0.445]\end{array}$ & $\begin{array}{l}0.025 \\
{[-0.147 \text { - }} \\
0.198]\end{array}$ \\
\hline Unadjusted p-value & $0.006 * * *$ & 0.981 & $0.017 * *$ & 0.477 & $0.003 * * *$ & {$[0.772]$} \\
\hline R-W p-value & $0.009 * * *$ & 0.98 & $0.013 * *$ & 0.726 & & \\
\hline Observations & 1,093 & 1,212 & 1,096 & 1,211 & 1,099 & 1,222 \\
\hline $\begin{array}{l}\text { R-squared } \\
\text { Mean Treatment }\end{array}$ & 0.043 & 0.064 & 0.028 & 0.042 & 0.055 & 0.079 \\
\hline $\begin{array}{l}\text { Endline } \\
\text { Mean Control }\end{array}$ & 0.131 & 0.066 & 0.176 & 0.06 & 0.226 & 0.114 \\
\hline Endline & -0.109 & 0.024 & -0.0498 & -0.019 & -0.0516 & 0.040 \\
\hline
\end{tabular}

Notes: $* * * \mathrm{p}<0.01, * * \mathrm{p}<0.05, * \mathrm{p}<0.1$. Confidence intervals clustered at community levels in squared brackets. R-W p-values were adjusted for multiple testing using the Romano-Wolf $(2005,2016)$ step-down method with 2,000 iterations and standard errors clustered at community level.

The table above presents intent-to-treat effects on each outcome for the full sample and stratified by child gender, household poverty, and place of residence. Models were estimated through OLS. For each outcome, the model controls for its baseline value, a dichotomous variable related to the randomized assignment to school feeding, and region dummies. Household poverty is a dichotomous indicator having the value of one if the household had baseline per capita consumption levels falling below the national consumption poverty line in 2013. Northern regions include Upper West, Upper East, and Northern region. Southern regions include Western, Central, Greater Accra, Volta, Eastern, Asanti, Brong Ahafo. 


\section{Appendix 1. Literature review on the effects of school feeding on child learning}

Table A.1 presents an overview of all school feeding experiments that we are aware of in lowand middle-income countries (LMICs). Notably, none of those studies evaluate government programs. Further, most of them evaluated effects on child nutrition outcomes, and to a lesser extent, cognition, while fewer studies have assessed effects on educational outcomes. Within the latter set, the vast majority evaluated impacts on schooling, with a consistent positive effect of school feeding programs on school enrolment and attendance, although with variation in effect sizes (Alderman and Bundy 2012; Drake et al. 2017). By contrast, fewer experiments have provided evidence on the impacts of school feeding on learning. Finally, last column of Table A.1 shows that heterogeneity analysis by child and household characteristics such as gender or poverty status is also limited. Most studies that assess heterogeneity focus on initial nutritional status. as they are small-scale efficacy trials of nutritionally-fortified meals, snacks or beverage administered at school.

The remainder of this section presents more detailed evidence from school feeding trials that focus on learning outcomes in both primary and preprimary schools in LMICs and discusses reasons for variation in treatment effects. For a meta-analysis of learning effects combining different school feeding interventions, see Snilstveit et al. (2015).

With regards to Sub-Saharan Africa, after one year of implementation, a field experiment evaluating different implementation modalities of the World Food Programme school feeding program in primary schools in internally-displaced people camps in Northern Uganda showed that the school feeding increased math for girls only (Alderman, Gilligan, and Lehrer 2012). A two-year randomized trial set in 12 schools in one rural district in Kenya focusing on providing 
meat, milk, and an "energy" meal to 360 primary school-children as a mid-morning snack, documented improved arithmetic test scores for children in the meat and milk groups (Neumann et al. 2007; Hulett et al. 2014; Whaley et al. 2003). Another study conducted in two districts in Western Kenya documented that a preschool breakfast program run by a Dutch NGO increases in preschoolers' curricula test scores, but only for those children attending more often and that had a more experienced teacher (Vermeersch and Kremer 2005). In Central and Southern America, a randomized trial in 16 rural Jamaican schools showed that primary school children receiving a school breakfast increased their math achievements, and effects were stronger among undernourished children (Grantham-McGregor, Chang, and Walker 1998; Powell et al. 1998). In rural Peru, a breakfast program improved performance on a vocabulary assessment among heavier children (Jacoby, Cueto, and Pollitt 1996).

With regards to Asian countries, recently, two trials have used the infrastructure of the Indian school feeding program to scale up food fortification, with no average effects on learning (Berry et al. 2018; Krämer, Kumar, and Vollmer 2018). However, Krämer et al. found positive treatment effects of about 0.2 standard deviations on math and reading for pupils who had more than 80 or 90 percent school-attendance. In Bangladesh, Ahmed (2004) evaluated the impact of mid-morning snack consisting of eight fortified wheat biscuits to around one million children in approximately 6,000 primary schools in highly food-insecure rural areas, plus four slum areas in Dhaka City, which was implemented by the World Food Programme. The snack improved test scores by 15.7 percent points, with larger effects on math. Students from urban slums did better in achievement tests than students from rural areas, probably due to better quality urban schools. Finally, in urban central Jakarta, Indonesia, 384 children across six schools were randomly assigned to different intervention groups related to administration of: (i) micronutrients; (ii) fatty 
acids; (iii) both; (iv) control. No effects on reading comprehension were detected (Osendarp et al. 2007).

Mixed findings in existing literature can be attributed, on the one hand, to differences in study methodologies and in target populations (e.g. child age, rural vs. urban, etc.), as well in variation in program implementation (e.g. modality of feeding, type of foods administered, quality and length of program implementation, etc.). On the other, school meals might not be enough to raise schooling achievements in settings where complementary educational inputs such as teachers or infrastructure are lacking or are of poor quality. Also, the offer of the meal can increase enrolment and, if educational inputs are fixed, the quality of overall learning inputs may decrease. Similarly, the offer of school meals may have composition effects and peer effects by attracting new students that are of often of less advantaged backgrounds and that tend to have lower achievements when entering school. Additionally, in contexts where food insecurity is especially high, the transfer might not be able to offset the opportunity costs of child labor. Further, households may redistribute food away from the child receiving school meals, potentially offsetting their nutritional benefits. Finally, school meals may not be effective in raising learning outcomes for fairly well-nourished populations. While this last hypothesis may be less salient in LMICs (though the Peruvian trial mentioned above may demonstrate otherwise), evidence from Australia, United Kingdom or the United States show that school feeding can improve learning achievements even among population were undernutrition is less of a policy concern (Osendarp et al. 2007; Belot and James 2011; Figlio and Winicki 2005).

\section{References Appendix}

Ahmed, Akhter U. 2004. "Impact of Feeding Children in School: Evidence from Bangladesh." 
IFPRI Working Paper 2033: 20006-1002. Washington, DC: International Food Policy Research Institute. http://www.lcgbangladesh.org/FSN/reports/IFPRI Final Report_School Feeding in Bangladesh.pdf.

Alderman, Harold, and Donald Bundy. 2012. "School Feeding Programs and Development: Are We Framing the Question Correctly?" World Bank Research Observer 27 (2): 204-21. https://doi.org/10.1093/wbro/lkr005.

Alderman, Harold, Daniel O. Gilligan, and Kim Lehrer. 2012. "The Impact of Food for Education Programs on School Participation in Northern Uganda." Economic Development and Cultural Change 61 (1): 187-218. https://doi.org/10.1086/666949.

Andang'o, Pauline EA, Saskia JM Osendarp, Rosemary Ayah, Clive E. West, David L. Mwaniki, Corine A. De Wolf, Rob Kraaijenhagen, Frans J. Kok, and Hans Verhoef. 2007. "Efficacy of Iron-Fortified Whole Maize Flour on Iron Status of Schoolchildren in Kenya: A Randomised Controlled Trial.” Lancet 26; 369(9757):1799-1806. https://doi.org/10.1016/S0140-6736(07)60817-4.

Ash, Deborah M., Simon R. Tatala, Edward A. Frongillo, Godwin D. Ndossi, and Michael C. Latham. 2003. "Randomized Efficacy Trial of a Micronutrient-Fortified Beverage in Primary School Children in Tanzania." The American Journal of Clinical Nutrition 77(4): 891-898.

Aurino, Elisabetta. 2020. Data from "Replication Data for: School feeding and child learning in Ghana." Version 1. Harvard Dataverse, V1. https://doi.org/10.7910/DVN/40KVRW

Belot, Michèle, and Jonathan James. 2011. "Healthy School Meals and Educational Outcomes." Journal of Health Economics 30 (3): 489-504. https://doi.org/10.1016/J.JHEALECO.2011.02.003. 
Berry, James, S. Metha, P. Mukherjee, H. Ruebeck, and G. Kartini Shastry. 2018. "Inputs, Monitoring and Crowd-Out in India School-Based Health Interventions.” S-89206-INC-2. London: International Growth Center.

Drake, Lesley, Meena Fernandes, Elisabetta Aurino, Josephine Kiamba, Boitshepo Giyose, Carmen Burbano, Harold Alderman, Lu Mai, Arlene Mitchell, and Aulo Gelli. 2017. "School Feeding Programs in Middle Childhood and Adolescence." In Disease Control Priorities 3, edited by D. Bundy, N. De Silva, S. Horton, D. Jamison, and G.C. Patton. Washington, D.C.: The World Bank. http://dcp-3.org/sites/default/files/chapters/DCP3 CAHD_Ch 12.pdf.

Figlio, David N., and Joshua Winicki. 2005. "Food for Thought: The Effects of School Accountability Plans on School Nutrition.” Journal of Public Economics 89 (2-3): 381-94. https://doi.org/10.1016/J.JPUBECO.2003.10.007.

Grantham-McGregor, S M, S Chang, and S P Walker. 1998. "Evaluation of School Feeding Programs: Some Jamaican Examples.” The American Journal of Clinical Nutrition 67 (4): 785S-789S. http://www.ncbi.nlm.nih.gov/pubmed/9537629.

Hulett, Judie L., Robert E. Weiss, Nimrod O. Bwibo, Osman M. Galal, Natalie Drorbaugh, and Charlotte G. Neumann. 2014. “Animal Source Foods Have a Positive Impact on the Primary School Test Scores of Kenyan Schoolchildren in a Cluster-Randomised, Controlled Feeding Intervention Trial.” British Journal of Nutrition 111 (05): 875-86. https://doi.org/10.1017/S0007114513003310.

Jacoby, Enrique, Santiago Cueto, and Ernesto Pollitt. 1996. "Benefits of a School Breakfast Programme among Andean Children in Huaraz, Peru.” Food and Nutrition Bulletin 17 (1): 
1-11. https://doi.org/10.1177/156482659601700111.

Kazianga, H., D. de Walque, and H. Alderman. 2012. "Educational and Child Labour Impacts of Two Food-for-Education Schemes: Evidence from a Randomised Trial in Rural Burkina Faso." Journal of African Economies 21 (5): 723-60. https://doi.org/10.1093/jae/ejs010.

Krämer, Marion; Kumar, Santosh; Vollmer, Sebastian. 2018. "Improving Children Health and Cognition: Evidence from School-Based Nutrition Intervention in India.” 203. GLO Discussion Paper No. 203. Maastricht: Global Labor Organization.

Lawson, Ty M. 2012. "Impact of School Feeding Programs on Educational, Nutritional, and Agricultural Development Goals: A Systematic Review of Literature.” Michigan State University. https://www.3ieimpact.org/evidence-hub/systematic-review-repository/impactschool-feeding-programs-educational-nutritional.

Moretti, Diego, Michael B. Zimmermann, Sumithra Muthayya, Prashanth Thankachan, Tung Ching Lee, Anura V. Kurpad, and Richard F. Hurrell. 2006. "Extruded Rice Fortified with Micronized Ground Ferric Pyrophosphate Reduces Iron Deficiency in Indian Schoolchildren: A Double-Blind Randomized Controlled Trial1-3." American Journal of Clinical Nutrition 84(4):822-829. https://doi.org/10.1093/ajen/84.4.822.

Muthayya, Sumithra, Tinku Thomas, Krishnamachari Srinivasan, Kirthi Rao, Anura V. Kurpad, Jan Willem van Klinken, Gail Owen, and Eveline A. de Bruin. 2007. "Consumption of a Mid-Morning Snack Improves Memory but Not Attention in School Children.” Physiology and Behavior 90(1): 142-150. https://doi.org/10.1016/j.physbeh.2006.09.025.

Neumann, Charlotte G, Suzanne P Murphy, Connie Gewa, Monika Grillenberger, and Nimrod O Bwibo. 2007. "Meat Supplementation Improves Growth, Cognitive, and Behavioral 
Outcomes in Kenyan Children." The Journal of Nutrition 137 (4): 1119-23. http://www.ncbi.nlm.nih.gov/pubmed/17374691.

Osendarp, Saskia J.M., Katrine I. Baghurst, Janet Bryan, Eva Calvaresi, Donna Hughes, Mahdin Hussaini, Elvina Karyadi, et al. 2007. "Effect of a 12-Mo Micronutrient Intervention on Learning and Memory in Well-Nourished and Marginally Nourished School-Aged Children: 2 Parallel, Randomized, Placebo-Controlled Studies in Australia and Indonesia." American Journal of Clinical Nutrition 86(4): 1082-93.

Powell, C A, S P Walker, S M Chang, and S M Grantham-McGregor. 1998. "Nutrition and Education: A Randomized Trial of the Effects of Breakfast in Rural Primary School Children." The American Journal of Clinical Nutrition 68 (4): 873-79. http://www.ncbi.nlm.nih.gov/pubmed/9771865.

Radhika, Madhari S., Krishnapillai M. Nair, Rachakulla Hari Kumar, Mendu Vishnuvardhana Rao, Punjal Ravinder, Chitty Gal Reddy, and Ginnela N.V. Brahmam. 2011. “Micronized Ferric Pyrophosphate Supplied through Extruded Rice Kernels Improves Body Iron Stores in Children: A Double-Blind, Randomized, Placebo-Controlled Midday Meal Feeding Trial in Indian Schoolchildren." American Journal of Clinical Nutrition 94(5):1202-10. https://doi.org/10.3945/ajen.110.007179.

Snilstveit, Birte, Jennifer Stevenson, Daniel Phillips, Martina Vojtkova, Emma Gallagher, Tanja Schmidt, Hannah Jobse, Maisie Geelen, Maria Grazia Pastorello, and John Eyers. 2015. "Interventions for Improving Learning Outcomes and Access to Education in Low- and Middle-Income Countries: A Systematic Review.” London: 3ie.

Stuijvenberg, M E van, J D Kvalsvig, M Faber, M Kruger, D G Kenoyer, and a J Benadé. 1999. 
"Effect of Iron-, Iodine-, and Beta-Carotene-Fortified Biscuits on the Micronutrient Status of Primary School Children: A Randomized Controlled Trial.” The American Journal of Clinical Nutrition 69 (3): 497-503.

Vermeersch, Christel, and Michael Kremer. 2005. "School Meals, Educational Achievement, and School Competition: Evidence from a Randomized Evaluation.” Policy Research Working Paper 3523. Washington, DC: The World Bank. https://doi.org/10.2139/ssrn.667881.

Whaley, Shannon E., Marian Sigman, Charlotte Neumann, Nimrod Bwibo, Donald Guthrie, Robert E. Weiss, Susan Alber, and Suzanne P. Murphy. 2003. "The Impact of Dietary Intervention on the Cognitive Development of Kenyan School Children.” The Journal of Nutrition 133(11): 3965S-3971S. https://doi.org/10.1093/jn/133.11.3965s.

Zimmermann, Michael B., Christophe Zeder, Noureddine Chaouki, Amina Saad, Toni Torresani, and Richard F. Hurrell. 2003. "Dual Fortification of Salt with Iodine and Microencapsulated Iron: A Randomized, Double-Blind, Controlled Trial in Moroccan Schoolchildren.” American Journal of Clinical Nutrition 77(2): 425-432. https://doi.org/10.1093/ajen/77.2.425.

Table A.1.

Summary characteristics of existing randomized control trials of school feeding in low- and middle-income countries

\begin{tabular}{|l|l|l|l|l|l|l|l|l|l|}
\hline Study & Locatio & Duration & Treatment & Implemente & Geograph & Outcomes & Heterogeneity \\
& $\mathbf{n}$ & & & $\mathbf{r}$ & ical area & & & analysis & by \\
child & or
\end{tabular}




\begin{tabular}{|c|c|c|c|c|c|c|c|c|}
\hline & & & & & & & & $\begin{array}{l}\text { household } \\
\text { backgrounds }\end{array}$ \\
\hline 1 & $\begin{array}{l}\text { Ahmed } \\
(2004)\end{array}$ & $\begin{array}{l}\text { Bangla } \\
\text { desh }\end{array}$ & $\begin{array}{l}14 \\
\text { months }\end{array}$ & Snack & $\begin{array}{ll}\text { WFP and } \\
\text { partner } \\
\text { NGOs }\end{array}$ & 9 districts & $\begin{array}{l}\text { Schooling; } \\
\text { learning; } \\
\text { nutrition }\end{array}$ & - \\
\hline 2 & $\begin{array}{l}\text { Alderman } \\
\text { et al., } \\
(2012)\end{array}$ & $\begin{array}{l}\text { Refuge } \\
\text { e camps } \\
\text { in } \\
\text { Norther } \\
\mathrm{n} \\
\text { Uganda }\end{array}$ & $\begin{array}{l}28 \\
\text { months }\end{array}$ & $\begin{array}{l}\text { School } \\
\text { feeding or } \\
\text { take-home } \\
\text { rations }\end{array}$ & WFP & $\begin{array}{l}10 \text { refugee } \\
\text { camps }\end{array}$ & Schooling & $\begin{array}{l}\text { Age } \\
\text { Gender }\end{array}$ \\
\hline 3 & $\begin{array}{l}\text { Andang'o } \\
\text { et al. } \\
(2007)\end{array}$ & Kenya & 5 months & $\begin{array}{l}\text { Fortified } \\
\text { maize }\end{array}$ & Researchers & 4 schools & Nutrition & - \\
\hline 4 & $\begin{array}{l}\text { Ash et al., } \\
(2003)\end{array}$ & $\begin{array}{l}\text { Tanzani } \\
\text { a }\end{array}$ & 6 months & $\begin{array}{l}\text { Fortified } \\
\text { beverages }\end{array}$ & Researchers & $\begin{array}{l}6 \text { primary } \\
\text { schools }\end{array}$ & Nutrition & $\begin{array}{l}\text { Initial } \\
\text { nutritional } \\
\text { status }\end{array}$ \\
\hline 5 & $\begin{array}{l}\text { Berry et al. } \\
(2018)\end{array}$ & $\begin{array}{l}\text { Odisha } \\
\text { (India) }\end{array}$ & 3 years & $\begin{array}{l}\text { Micronutrien } \\
\mathrm{t} \\
\text { supplementat } \\
\text { ion in } \\
\text { existing } \\
\text { program }\end{array}$ & Researchers & 1 district & Nutrition & $\begin{array}{l}\text { Initial } \\
\text { nutritional } \\
\text { status }\end{array}$ \\
\hline 6 & $\begin{array}{l}\text { Grantham- } \\
\text { McGregor } \\
\text { et al., } \\
\text { (1998) }\end{array}$ & Jamaica & 21 weeks & Breakfast & Researchers & $\begin{array}{l}4 \quad \text { rural } \\
\text { primary } \\
\text { schools }\end{array}$ & Cognition & $\begin{array}{l}\text { Initial } \\
\text { nutritional } \\
\text { status }\end{array}$ \\
\hline 7 & $\begin{array}{l}\text { Kazianga et } \\
\text { al., (2012) }\end{array}$ & $\begin{array}{l}\text { Norther } \\
\mathrm{n} \\
\text { Burkina } \\
\text { Faso }\end{array}$ & 1 year & $\begin{array}{l}\text { School } \\
\text { feeding or } \\
\text { take-home } \\
\text { rations }\end{array}$ & WFP & 46 schools & $\begin{array}{l}\text { Schooling; } \\
\text { labor }\end{array}$ & Gender \\
\hline
\end{tabular}


Aurino, Gelli, Adamba, Osei-Akoto, Alderman 71

\begin{tabular}{|c|c|c|c|c|c|c|c|c|}
\hline 8 & $\begin{array}{l}\text { Kramer et } \\
\text { al. (2018) }\end{array}$ & $\begin{array}{l}\text { Bihar } \\
\text { (India) }\end{array}$ & 1 year & $\begin{array}{l}\text { Micronutrien } \\
\mathrm{t} \\
\text { supplementat } \\
\text { ion in } \\
\text { existing } \\
\text { program }\end{array}$ & Researchers & $\begin{array}{l}\text { Two } \\
\text { blocks of } \\
\text { Jenahabad } \\
\text { district }\end{array}$ & $\begin{array}{l}\text { Nutrition; } \\
\text { cognition; } \\
\text { learning }\end{array}$ & - \\
\hline 9 & $\begin{array}{l}\text { Jacoby et } \\
\text { al. (1996) }\end{array}$ & Peru & 3 months & Breakfast & Researchers & $\begin{array}{l}\text { Ten } \\
\text { schools }\end{array}$ & $\begin{array}{l}\text { Nutrition; } \\
\text { schooling; } \\
\text { learning }\end{array}$ & $\begin{array}{l}\text { Initial } \\
\text { nutritional } \\
\text { status }\end{array}$ \\
\hline 10 & $\begin{array}{l}\text { Moretti et } \\
\text { al. (2006) }\end{array}$ & $\begin{array}{l}\text { Bangal } \\
\text { ore } \\
\text { (India) }\end{array}$ & 9 months & Fortified rice & Researchers & 1 school & Nutrition & - \\
\hline 11 & $\begin{array}{l}\text { Muthayya } \\
\text { et al., } \\
(2007)\end{array}$ & $\begin{array}{l}\text { Urban } \\
\text { Bangal } \\
\text { ore, } \\
\text { India` }\end{array}$ & 1 year & Snack & Researchers & $\begin{array}{l}69 \\
\text { children }\end{array}$ & Cognition & - \\
\hline 12 & $\begin{array}{l}\text { Osendarp } \\
\text { et al., } \\
(2007)\end{array}$ & $\begin{array}{l}\text { Urban } \\
\text { Jakarta, } \\
\text { Indones } \\
\text { ia }\end{array}$ & 1 year & Snack & Researchers & 6 schools & $\begin{array}{l}\text { Nutrition; } \\
\text { cognition; } \\
\text { learning }\end{array}$ & - \\
\hline 13 & $\begin{array}{l}\text { Radhika et } \\
\text { al. (2011) }\end{array}$ & $\begin{array}{l}\text { Andhra } \\
\text { Pradesh } \\
\text { (India) }\end{array}$ & 8 months & Fortified rice & Researchers & 1 school & Nutrition & - \\
\hline 14 & $\begin{array}{l}\text { van } \\
\text { Stuijvenber } \\
\text { g et al., } \\
(1999)\end{array}$ & $\begin{array}{l}\text { South } \\
\text { Africa }\end{array}$ & 1 year & $\begin{array}{l}\text { Snack and } \\
\text { beverage }\end{array}$ & Researchers & 1 school & $\begin{array}{l}\text { Nutrition; } \\
\text { cognition; } \\
\text { schooling; } \\
\text { morbidity }\end{array}$ & - \\
\hline 15 & $\begin{array}{l}\text { Vermeersc } \\
\mathrm{h} \quad \text { and } \\
\text { Kremer } \\
(2005)\end{array}$ & $\begin{array}{l}\text { Wester } \\
\mathrm{n} \\
\text { Kenya }\end{array}$ & 2 years & Breakfast & NGO & $\begin{array}{l}25 \text { schools } \\
\text { in } 2 \\
\text { districts }\end{array}$ & Learning & Gender \\
\hline
\end{tabular}




\begin{tabular}{|l|l|l|l|l|l|l|l|l|}
\hline 16 & Whaley et & Kenya & 21 & School & Researchers & 12 schools & Learning & - \\
al., (2003); & & months & feeding & & & \\
Hulett et al. & & & & & & \\
(2014); & Neumann \\
et al. & & & & & & & & \\
$(2007)$ & & & & & & & \\
\hline 17 & $\begin{array}{l}\text { Zimmerma } \\
\text { nn et al. }\end{array}$ & Morocc & 9 months & Fortified salt & Researchers & 2 schools & Nutrition & - \\
$(2003)$ & & & & & & & \\
\hline
\end{tabular}

Notes: the table above provides characteristics in terms of implementer, duration, program type, geographical areas and outcomes analyzed of existing randomized trials of school feeding. Studies were first identified through the systematic review conducted in 2012 by Lawson (Lawson 2012), which the authors had updated. WFP: World Food Programme

${ }^{i}$ The government approved an expansion of the program to over 3 million children by July 2016 , but data on actual coverage are not currently available (http://mogcsp.gov.gh/ghana-schoolfeeding-programme-gsfp/). Although the program covers all districts of Ghana from the academic year 2016/17, it does not cover all schools. Plans to expand in-school meals for all public schools in Ghana are on-going.

ii The results of the analyses on child anthropometrics and community agriculture are part of separate analyses, as per our protocol.

iii We thank the reviewers for highlighting this perspective. 
iv This is different from pairwise matching, whereby clusters are paired based on background characteristics, before randomly assigning one cluster within each pair to treatment assignment. This approach the advantage of enabling balance on more variables than with the stratification randomization method, and to provide balance in means on continuous variables (Bruhn and McKenzie 2009).

${ }^{v}$ The design also included an agricultural sub-study within the intervention group to test whether stimulating the procurement of school food from district-based farmers for half of the GSFP schools would stimulate district-level agricultural outcomes. Treatment assignment to this second level of randomization was achieved through a restricted randomization procedure that was similar to the one to assign the intervention to a random subset of schools. Such procedure was developed to allocate the school feeding arm into two sub-groups (GSFP and Home-grown school feeding, HGSF), based on variables that characterized the agricultural environment at the district level, including agroecological zone, maize productivity, employment. The basic idea of the multi-level design of the trial was to compare child-level outcomes (For example,, education, health) between children belonging to school feeding and control communities, and the agriculture impacts of the HGSF pilot relative to the regular GSFP at the district-level. Thus, all the analysis we undertake in this paper pools GSFP and HGSF in a single school feeding arm. Also, we note that the type of program to which a child was assigned (e.g, standard GSFP viz. HGSF pilot) was not predictive of uptake (Supplementary online materials 3), and that in Supplementary online materials 10 we show that treatment effects do not differ by these subgroups. Both checks reassure about potential concerns of implementation variation between schools in districts that were randomly assigned to different food procurement schemes could have affected in some way the educational outcomes. 
${ }^{\text {vi }}$ In the case of young children, the caregiver reported on schooling.

vii This result did not change when we split treatment in GSFP and HGSF pilots (results available upon request).

viii Focus groups with parents highlighted that a proportion of children ate less at home because they were less hungry due to the school meals, which may explain this finding. At a descriptive level, having a under-5 sibling at home was not associated with bringing home food from school, which reassures about potential intra-household substitution effects (Fernandes et al. 2017) ix Controlling for interviewer dummies is a common practice in similar standardizations. It also helped tackling potential language effects, as unfortunately we do not have information on the specific language of test administration. The interviewer spoke the same language of the child. ${ }^{x}$ Although children were given assessments in all tests, discrepancies in sample sizes across raw and standardised scores reflect inability to convert raw scores into standardised scores (For example, lack of child age in months). A similar issue is highlighted in Graff Zivin and coauthors (Graff Zivin, Hsiang, and Neidell 2018). This could be a potential concern if the missing scores correlate with treatment assignment. Regressions of treatment on score availability rules out this hypothesis, as the coefficients are zero and not statistically significant across all outcomes (results available upon request).

${ }^{\mathrm{xi}}$ A similar picture emerged from the analysis of baseline differences in raw scores for the baseline sample prior to attrition presented in Online Appendix 5. This provides a further reassurance about potential biases in treatment effects of school feeding on child learning stemming from nonrandom attrition.

xii McKenzie (2012), for instance, posits that low autocorrelation ranges between $\rho=0.2$ to 0.4 . 
xiii Results are unchanged when a dummy variable for missing baseline test score is included (results available upon request). Missing observations at baseline explain the difference in terms of number of observations between the ANCOVA and DiD estimations.

xiv We opted for this approach, as compared to a different one in which we would interact school feeding with the policy group of interest, for different reasons. First, we wanted to estimate the total effect of the policy on each sub-group, and, second, because the stratification has the advantage that the separate regressions allow all parameters to vary by subgroup. Nonetheless, we tested the differential effect in the intervention between each of the comparison groups in a pooled regression model with interactions, and the Romano-Wolf adjusted $\mathrm{p}$-values are around $\mathrm{p}$ $\sim \sim 0.1$ in the case of gender and household poverty (results available upon request).

${ }^{x v}$ In the context of Ghana, Duflo et al. (Duflo, Dupas, and Kremer 2017) have recently assessed the medium-term effects of secondary school scholarships. After eight years, scholarship winners had higher schooling, scored on average 0.15 greater in math and literacy, had better health behaviors, and girls had less children.

${ }^{\text {xvi }}$ For instance, Gelli and Darayani show that between 2005 and 2008, the costs of school feeding increased by 12 percent and 24 percent, on average, in middle- and low-income countries, respectively. 